\title{
The NPOESS Airborne Sounding Testbed Interferometer-Remotely Sensed Surface and Atmospheric Conditions during CLAMS
}

\author{
W. L. SMith SR. \\ Hampton University, Hampton, Virginia \\ D. K. ZHOU AND A. M. LARAR \\ NASA Langley Research Center, Hampton, Virginia \\ S. A. MAngo \\ NPOESS Integrated Program Office, Silver Spring, Maryland \\ H. B. Howell, R. O. Knuteson, And H. E. Revercomb \\ University of Wisconsin-Madison, Madison, Wisconsin \\ W. L. SMITH JR. \\ NASA Langley Research Center, Hampton, Virginia
}

(Manuscript received 26 October 2003, in final form 21 May 2004)

\begin{abstract}
During the Chesapeake Lighthouse and Aircraft Measurements for Satellites (CLAMS), the National Polar-orbiting Operational Environmental Satellite System (NPOESS) Airborne Sounder TestbedInterferometer (NAST-I), flying aboard the high-altitude Proteus aircraft, observed the spatial distribution of infrared radiance across the $650-2700 \mathrm{~cm}^{-1}(3.7-15.4 \mu \mathrm{m})$ spectral region with a spectral resolution of $0.25 \mathrm{~cm}^{-1}$. NAST-I scans cross track with a moderate spatial resolution (a linear ground resolution equal to $13 \%$ of the aircraft altitude at nadir). The broad spectral coverage and high spectral resolution of this instrument provides abundant information about the surface and three-dimensional state of the atmosphere. In this paper, the NAST-I measurements and geophysical product retrieval methodology employed for CLAMS are described. Example results of surface properties and atmospheric temperature, water vapor, ozone, and carbon monoxide distributions are provided. The CLAMS NAST-I geophysical dataset is available for use by the scientific community.
\end{abstract}

\section{Introduction}

The National Polar-orbiting Operational Environmental Satellite System (NPOESS) Integrated Program Office led the development of the NPOESS Airborne Sounder Testbed (NAST) system. The purpose of the NAST is to conduct high-altitude aircraft infrared and microwave measurements for the purpose of validating radiance observations from present and future satellite sounding systems, such as the Cross-track Infrared Sounder (CrIS) and the Advanced Technology Microwave Sounder (ATMS) to fly on the NPOESS Preparatory Program (NPP) satellite and the follow-on

Corresponding author address: William L. Smith Sr., Center for Atmospheric Studies, 23 Tyler St., Hampton, VA 23668.

E-mail: bill.smith@hamptonu.edu
NPOESS. The Massachusetts Institute of Technology Lincoln Laboratory (MIT-LL) built the NAST Interferometer component (NAST-I), with its internal blackbody calibration system being provided by the University of Wisconsin Space Science and Engineering Center (UW-SSEC). NAST-I is a Fourier transform spectrometer of the Michelson interferometer design. It possesses high spectral resolution $\left(0.25 \mathrm{~cm}^{-1}\right)$ and high spatial resolution $(0.13-\mathrm{km}$ linear ground resolution per kilometer of aircraft flight altitude at nadir). The NAST-I spatially scans cross-track to the aircraft motion $\pm 48.2^{\circ}$, thereby providing a $2.3-\mathrm{km}$ ground track swath width per kilometer of aircraft flight altitude (e.g., a 46-km swath from a flight altitude of $20 \mathrm{~km}$ ). The radiometric noise is nominally $0.3 \mathrm{~K}$, spectrum to spectrum, dependent upon spectral region and scene temperature. The spectrally random noise, spectral 


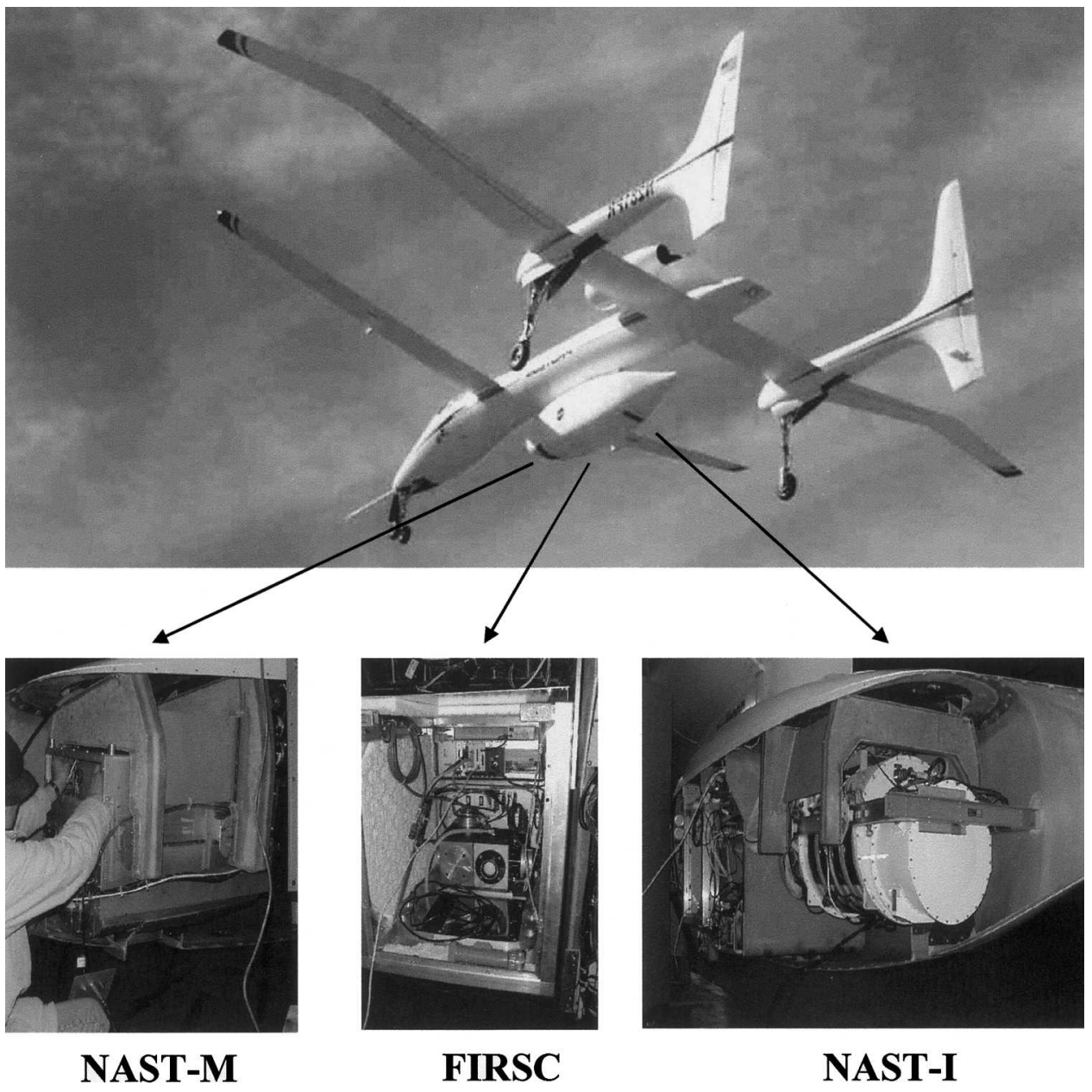

FIG. 1. NAST-M, NAST-I, and FIRSC instruments flown on the Proteus aircraft during CLAMS.

point to spectral point, is generally smaller than $0.3 \mathrm{~K}$ within a given radiance spectrum. It is the spectrally random component of the radiance measurement noise that limits the ability to deconvolute the radiance spectrum with the precision needed to retrieve small-scale vertical features of atmospheric temperature and the absorbing constituents (e.g., water vapor). NAST-I is designed to support the development and performance validation of high spectral (i.e., vertical) resolution temperature and moisture sounders being flown on earthorbiting satellites. NAST-I data are also useful for testing inversion methods and for validating satellite retrievals of thermodynamic profiles used for weather prediction and chemical abundances (such as ozone and carbon monoxide) intended for monitoring air quality and supporting climate modeling. The resolution, precision, and accuracy of the NAST-I data products enable them to be used for depicting the state of the atmosphere and surface in support of scientific studies of environmental processes. NAST-I, aboard Proteus, collected high-quality data in support of the Chesapeake Lighthouse and Aircraft Measurements for Satellites
(CLAMS) experiment (Smith et al. 2001). In this paper, the NAST-I instrument, radiometric observation characteristics, and the forward and inverse models used for geophysical data retrieval are described. Examples of retrieved geophysical parameters derived from NAST-I observations recorded during Proteus flights in CLAMS are presented. The entire NAST-I radiance dataset obtained during CLAMS is available for use by the scientific research community (http://spigot.ssec. wisc.edu/ nasti/NASTI/).

\section{Instrument design}

The NAST-I instrument design is based on reflective optics, a $\mathrm{KBr}$ beamsplitter/compensator and separate integral detector/cooler assemblies operating at $77 \mathrm{~K}$. Two blackbody sources, one heated and one ambient (cold), are viewed once each scan to provide absolute radiometric calibration at a level better than $0.5 \mathrm{~K}$. Detector nonlinearity is accounted for using a physical algorithm whose coefficients are based on ground calibrations, which included an $\mathrm{LN}_{2}$ source and upward views of the cold sky background. The nonlinearity al- 


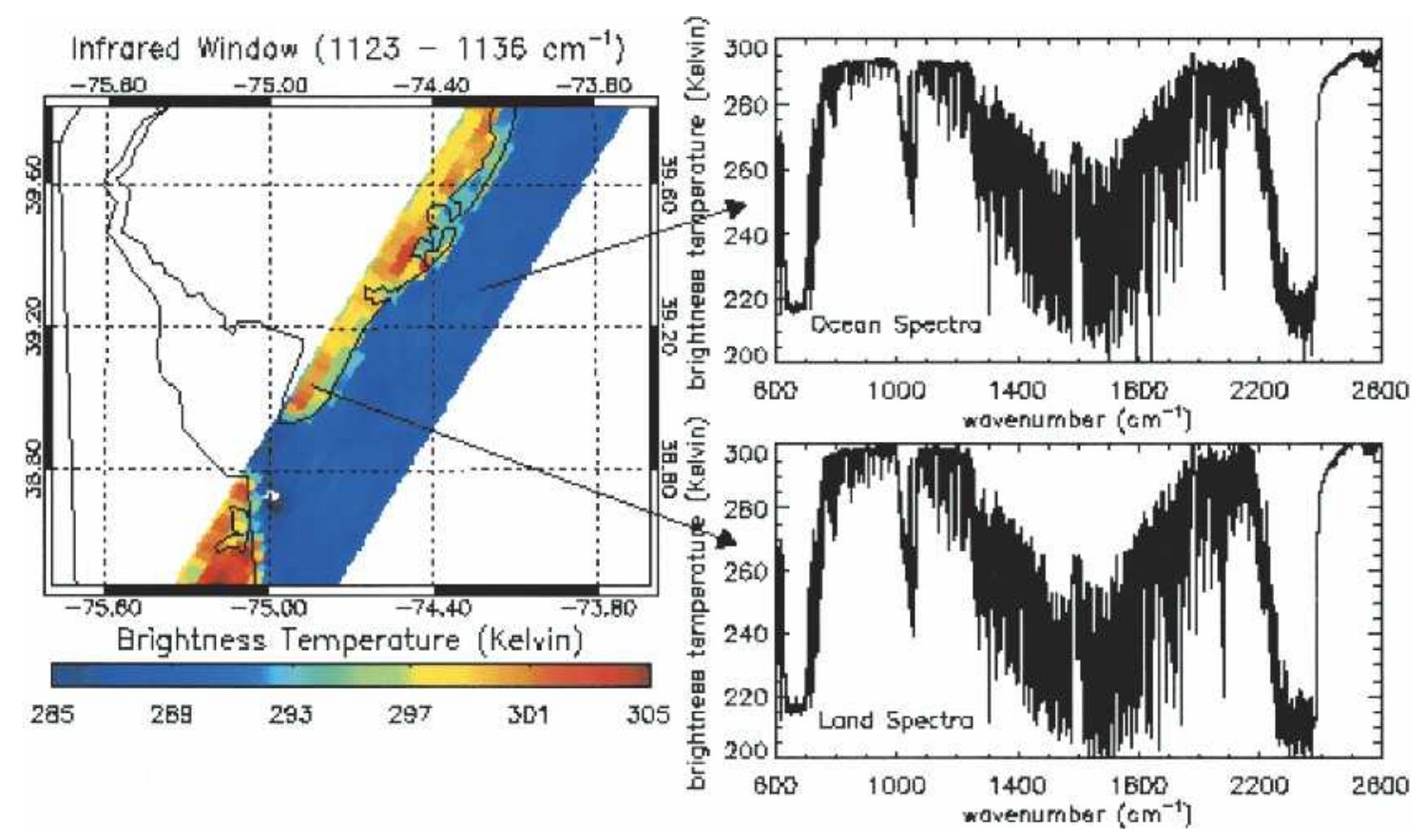

FIG. 2. NAST-I "window" imagery and example land and ocean radiance spectra for the CLAMS observation area.

gorithm was initially validated by coflying the NAST-I with the High Spectral Resolution Interferometer Sounder (HIS), which employed linear response ASi detectors cooled to liquid He temperatures (i.e., $6 \mathrm{~K}$ ). Dynamic alignment of the interferometer optics, a pressurized $\mathrm{N}_{2}$ enclosure and wire coil shock mounts are used to minimize the environmental effects of aircraft flight. The instrument processor/controller is based on a Pentium CPU with real-time digital signal processing. A ring laser gyro/GPS navigation sensor is used to earth-locate the data. Additional details are contained in publications by Cousins and Smith (1997), Revercomb et al. (1998), and Smith et al. (1999, 2001).

During CLAMS the NAST-I flew aboard the Proteus aircraft together with the NAST-M (the microwave radiometer component of NAST) and the Far-IR Sensor for Cirrus (FIRSC). Figure 1 shows the Proteus payload configuration for the CLAMS. From the nominal Proteus altitude of $16 \mathrm{~km}, \sim 2.2 \mathrm{~km}$ spatial resolution is achieved over a swath of $\sim 40 \mathrm{~km}$, thereby providing three-dimensional hyperspectral images of radiance and derived geophysical products (Fig. 2).

NAST-I radiance spectra cover $\mathrm{CO}_{2}$ emission within the $15-\mu \mathrm{m}$ and $4.3-\mu \mathrm{m}$ bands, $\mathrm{H}_{2} \mathrm{O}$ emission across the 6.3- $\mu \mathrm{m}$ band, $\mathrm{O}_{3}$ emission within the 9.6- $\mu \mathrm{m}$ and 4.7$\mu \mathrm{m}$ bands, and $\mathrm{CO}$ emission within the $4.6-\mu \mathrm{m}$ band. These radiance measurements can be used for retrieving atmospheric temperature, water vapor, ozone, and carbon monoxide profiles as well as for retrieving surface skin temperature and emissivity. NAST-I data were collected during the CLAMS experiment under a variety of meteorological conditions. To demonstrate typical characteristics of the retrieved geophysical NAST-I dataset, a complete set of results is presented for the CLAMS mapping flight over the Clouds and Earth's Radiant Energy System (CERES) Ocean Validation Experiment (COVE) site during 14 July 2001. The radiosonde and sea surface temperature observations at the COVE site $(25 \mathrm{~km}$ east of Virginia Beach, Virginia) are used to validate the NAST-I retrievals.

\section{Forward radiative transfer model}

A version of the optimal spectral sampling (OSS) fast radiative transfer model (Moncet et al. 2001; Liu et al. 2003) was used for NAST-I simulations and used in NAST-I retrieval algorithms. In the OSS approach, an extension of the exponential sum fitting transmittance method, radiance for each instrument channel is represented as a linear combination of radiances computed at a few preselected monochromatic frequencies within the domain spanned by the instrument line shape function. Like other fast radiative transfer models, the model parameters (i.e., the weights and locations for these monochromatic frequencies) are obtained offline by training under a variety of atmospheric and surface conditions for the NAST-I observation geometries. The optimal selection of the monochromatic frequencies and the computation of the weights are performed by minimizing the difference between the radiances derived using the approximate OSS formulation to those obtained with the reference Line-By-Line Radiative Transfer Model (i.e., LBLRTM). The NAST-I OSS model is designed to rapidly compute radiances and transmittances for several major atmospheric species 
(i.e., $\mathrm{CO}_{2}, \mathrm{H}_{2} \mathrm{O}, \mathrm{CH}_{4}, \mathrm{~N}_{2} \mathrm{O}, \mathrm{O}_{3}$, and $\mathrm{CO}$ ) from any aircraft/sensor altitude, which greatly benefits the airborne instrument like NAST-I in achieving accurate model simulation. The OSS is used rather than LBLRTM in order to be able to process the NAST-I data in approximately the same amount of time required to acquire the radiance measurements. Figure 3 (Liu 2004) shows the mean and standard deviation of the difference between OSS and LBLRTM calculations for the three spectral bands of NAST-I, computed for a diverse set of 108 independent atmospheric conditions (i.e., the NOAA-88 radiosonde sample). As can be seen, the errors in the OSS representation of the atmospheric radiance spectra are generally less than those expected due to instrumental noise (i.e., $<0.3 \mathrm{~K}$ ).

\section{Geophysical product retrieval method}

Three retrieval steps are taken to produce thermodynamic and trace gas constituent profile retrievals: (a) eigenvector regression, (b) matrix inversion, and (c) iterative adjustment. The approach is described in detail by Zhou et al. $(2002,2003,2005)$.

\section{a. Stage 1: Eigenvector regression}

\section{1) Overview}

Eigenvector regression follows the original work of Smith and Woolf (1976) in which the method was applied to the processing of Nimbus-6 satellite infrared and microwave sounding radiance observations. More recent satellite applications of this methodology is presented by Goldberg et al. (2003) where the methodology is used to process hyperspectral sounding data from the Aqua AIRS. In this method, the amplitudes of radiance eigenvectors are related to surface and atmospheric state variables using multiple linear regression. The optimal number of eigenvectors to be used in the regression retrieval is selected as that number which minimizes the difference between observed and retrieval-calculated radiance. The radiances used to produce the eigenvectors and regression relationships are physically based; that is, they are obtained from radiative transfer calculations based on radiosonde profiles for a particular geographical region and a particular season of the year. The OSS forward model is used for the radiative transfer calculations. In the simulation, the radiosonde temperature and humidity structure are used to diagnose the cloud-top level. For the spectral radiance calculations, each radiosonde that possesses cloud is treated as both a clear sky and as an opaque (i.e., "black" overcast) cloud condition profile. Since the eigenvector regression algorithm is linear, the opaque overcast cloud and clear-sky conditions are sufficient for producing regression relationships that represent the effects of gray clouds for any degree of opacity and/or fractional coverage. The opaque sky condition profile is created by representing the radiosonde
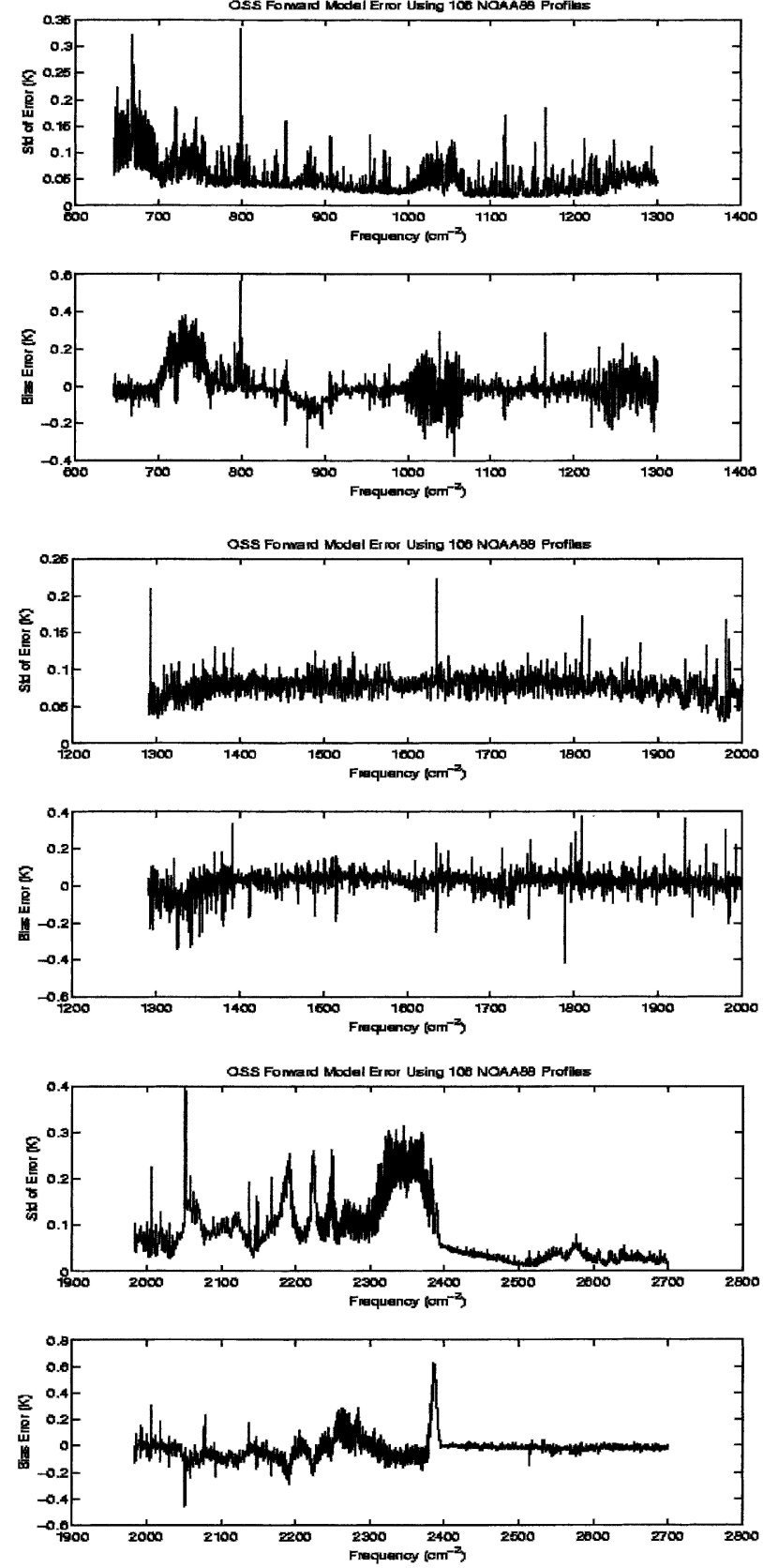

FIG. 3. Mean and standard deviation of the difference between OSS and LBRTM model calculations for an independent set of 108 diverse atmospheric conditions.

temperature and moisture profile below the cloud as isothermal, at cloud-top temperature, and saturated. This profile adjustment enables the retrieval system to obtain a clear-sky equivalent, from a radiative transfer point of view, temperature and moisture profile regardless of cloud condition. If the sky is cloud free, then the clear air atmospheric profile will be obtained from aircraft level down to the earth's surface. If an opaque cloud exists, the clear air atmospheric profiles will be retrieved down to cloud top with an isothermal, at 
cloud-top temperature, and a saturated profile being retrieved below the cloud top down to the earth's surface. If a semitransparent and/or broken cloud cover exists, then the clear air atmospheric profiles will be retrieved down to the cloud-top level with a temperature profile intermediate to the clear air profile and the cloud-top temperature, and a less than saturated water vapor condition, being retrieved below the cloud. In the semitransparent and/or broken-cloud condition, the proportion of isothermal and saturation structure retrieved below the cloud depends upon the cloud opacity and fraction. For the training, the surface emissivity spectrum for each radiosonde profile is randomly selected from a set of laboratory-measured emissivity spectra for a wide variety of surface types (Wilber et al. 1999; Salisbury and D'Aria, 1992). Trace gas species, such as ozone and carbon monoxide, were specified using a statistical representation based on correlations of these gases with temperature and humidity conditions specified by the radiosonde data.

Regression equations that relate the radiance eigenvector amplitudes to the radiosonde temperature and water vapor values, surface temperature, and the coefficients of an eigenvector representation of surface emissivity spectra used in the radiance simulation, are derived, assuming a different number of eigenvectors for representation of the spectral radiance information. In the application of the retrieval algorithm, the optimal number of eigenvectors to be used for the retrieval is selected as that number which minimizes the local rms difference between observed radiances and radiances calculated from the retrievals. The rationale is that if the number is too small then the rms difference will be large since the retrieval is not capturing the full information content of the radiance observations. On the other hand, if the number is too big, then the rms difference will also be large since the retrieval will be fitting random radiance measurement error causing the retrieval to exhibit abnormal oscillations. Thus, the number of eigenvectors that produces a spatial distribution of retrievals that optimizes the rms fit of retrieval-calculated radiances to observed radiances is presumed to be that which produces the smallest retrieval error. This number generally ranges between 15 and 50, for NAST-I, depending upon the meteorological variance and the observed radiance error associated with the particular dataset used (higher natural variance and lower random radiance measurement error requires a larger number of eigenvectors to represent the information content of the radiance spectra). The regression equations for the optimal set are then applied to NAST-I radiance measurements, which are corrected for reflected solar radiation contributions. The reflected solar contribution correction is based on a reflected solar spectrum calculated for a model surface and atmospheric condition, similar to that being observed, and the radiances observed in the $4.0-\mu \mathrm{m}$ and $9.0-\mu \mathrm{m}$ window regions of the spectrum. Since all the radiative transfer calculations and eigenvector decomposition analysis are done "offline" to the actual data processing, the algorithm is extremely fast when applied to real data. Detailed validations from NAST-I field campaigns have indicated that thermodynamic parameters (i.e., temperature and water vapor profiles) above cloud levels can be accurately retrieved using this physically based eigenvector regression method.

Since the retrieval problem is ill-posed, additional information is needed to constrain the solution for atmospheric profiles from radiance spectra. Here, radiosonde sample statistics constrain the regression algorithm and the result can be used as the initial profile to constrain a direct nonlinear mathematical inverse solution of the radiative transfer equation for the atmospheric profiles. The linear statistical eigenvector regression retrieval provides first-guess profiles and surface properties that minimize the number of iterations and computation time required for the radiative transfer inverse numerical processing.

\section{2) AnAlyticAl APPROACH}

The basic linear statistical regression theory is summarized as follows. Given a set of historical radiosonde measurements and associated simulated spectral radiance $R$, the relationship between an atmospheric state and associated radiances is expressed statistically in terms of regression coefficients. Here $R$ is calculated from the radiosonde atmospheric state and assumed surface properties $A\left(T, Q, T_{s}, \varepsilon_{s}\right)$, where $T$ is the temperature profile, $Q$ is the water vapor profile, $T_{s}$ is the surface temperature, and $\varepsilon_{s}$ is the surface emissivity. The use of amplitudes of statistical eigenvectors of radiance as the predictors acts to filter the radiance noise and effectively stabilizes the retrieval (Wark and Fleming 1966; Smith and Woolf 1976). The eigenvectors $\mathbf{E}$ [i.e., empirical orthogonal functions (EOFs)] can be generated using the covariance matrix $\mathbf{M}$ from a set of radiances associated with a radiosonde training dataset (total number of $\mathrm{S}$ profiles, and number of selected spectral channels denoted by nc). This covariance matrix is expressed as

$$
M_{i j}=\frac{1}{s} \sum_{k=1}^{s} \Re_{k i} \Re_{k j},
$$

where $\Re_{k j}$ is the radiance (deviation from the sample mean) at spectral position $j$ of radiosonde sample $k$. The eigenvectors, $\mathbf{E}$ of Eq. (1), are ordered from the largest amount of variance to the residual variance in successively decreasing order. The radiance eigenvector amplitude $\mathbf{C}$ (i.e., the radiance predictor in the eigenvector domain) is given by

$$
C_{i}=\sum_{j=1}^{n c} R_{j} E_{j i} .
$$

The statistical regression coefficient $K$ derived from a set of radiosonde observations provides the relation- 

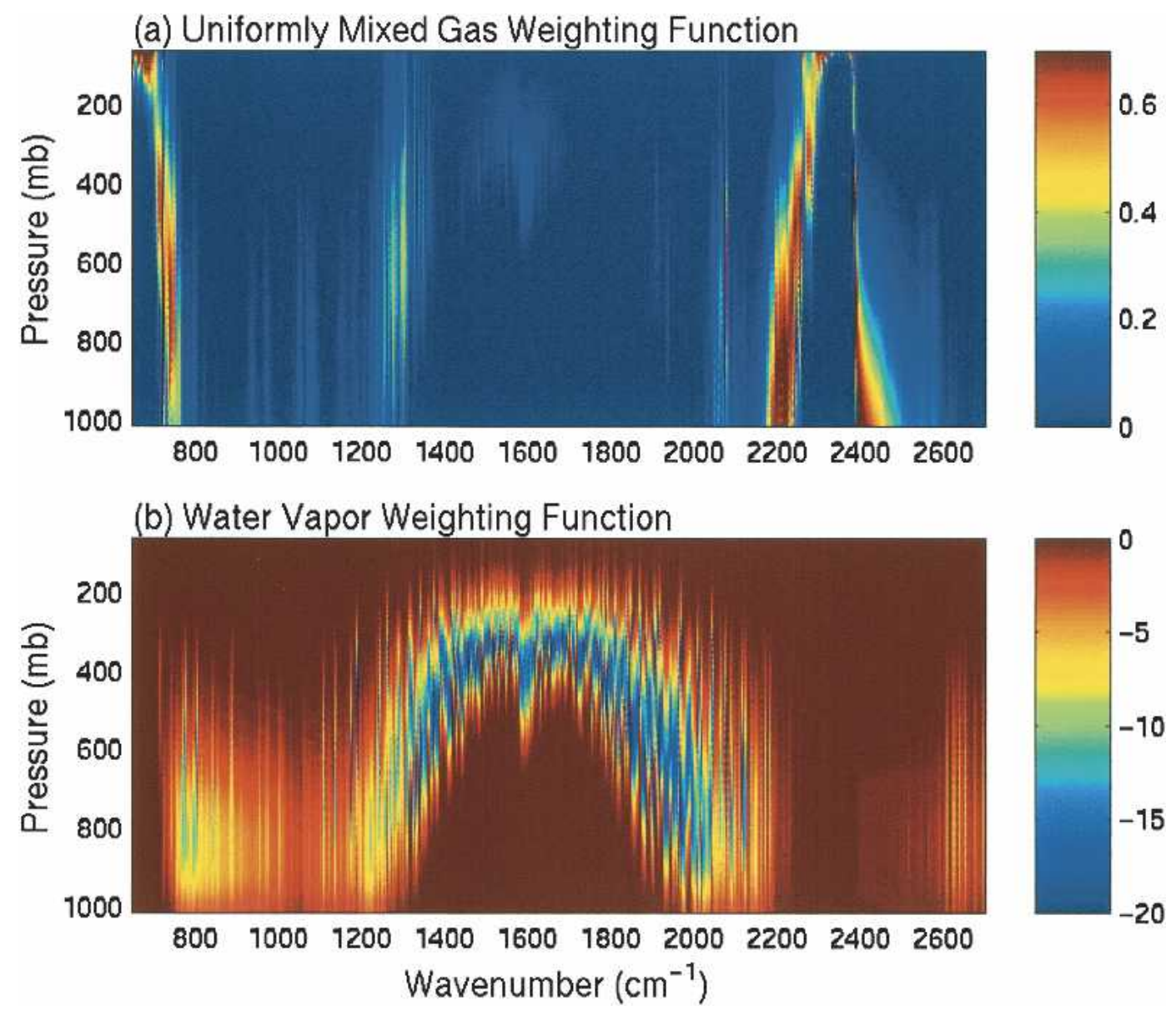

FIG. 4. The weighting function matrices of (a) fixed gas (constant mixing ratio) and (b) water vapor of NAST-I channels calculated with U.S. Standard Atmosphere, 1976. The peak (or valley) of the weighting function of fixed gas (or water vapor) of each channel indicated in wavenumber is associated with a pressure altitude.

ship between the surface and atmospheric variables, $A$, and associated radiances, $R$, and surface pressure, $P_{s}$ :

$$
A_{j}=\sum_{i=1}^{n-1} K_{j i} C_{i}+K_{j n} P_{s}=\sum_{i=1}^{n-1} K_{j i}\left(\sum_{l=1}^{n c} R_{l} E_{l i}\right)+K_{j n} P_{s},
$$

where $n$ is the number of EOFs (i.e., the number of principal components used for the regression retrieval). The surface emissivity can also be retrieved by predicting the amplitudes of a small set (i.e., five) of emissivity eigenvectors used to represent the laboratory sample of emissivity spectra utilized for the radiance simulations.

NAST-I contains a scanning mirror that allows the viewing angle to vary from $-45^{\circ}$ to $+45^{\circ}$ with a step of $7.5^{\circ}$ in the cross-track direction. The zenith angle is associated with the viewing angle and aircraft roll angle at each NAST-I scan position. The regression coefficients are derived for a fixed set of zenith angles, while the retrieval for a specific zenith angle of a scan is obtained by linearly interpolating the two retrievals ob- tained using regression coefficients for the two closest zenith angles. Regression coefficients are defined for as many angles necessary to correctly account for radiance dependence on zenith angle in the retrieval process.

\section{3) REGRESSION IMPLEMENTATION}

The CLAMS radiosonde training profiles were taken from July to September 1998. Radiosonde stations within $1600 \mathrm{~km}$ of Wallops Island, Virginia (totaling 24 stations), were used to provide about 2000 atmospheric profile conditions. The associated ozone profiles were synthetically produced using the regression statistics derived from the NASA Wallops Flight Facility (WFF) ozonesonde database collected between July 1995 and March 2000 [courtesy of H. Woolf, Cooperative Institute for Mesoscale Meteorological Studies (CIMSS)/ University of Wisconsin (UW), and F. Schmidlin, NASA WFF].

NAST-I possesses three spectral bands that together provide 8632 spectral channels. To limit the size of EOFs in order to accommodate the computer memory 


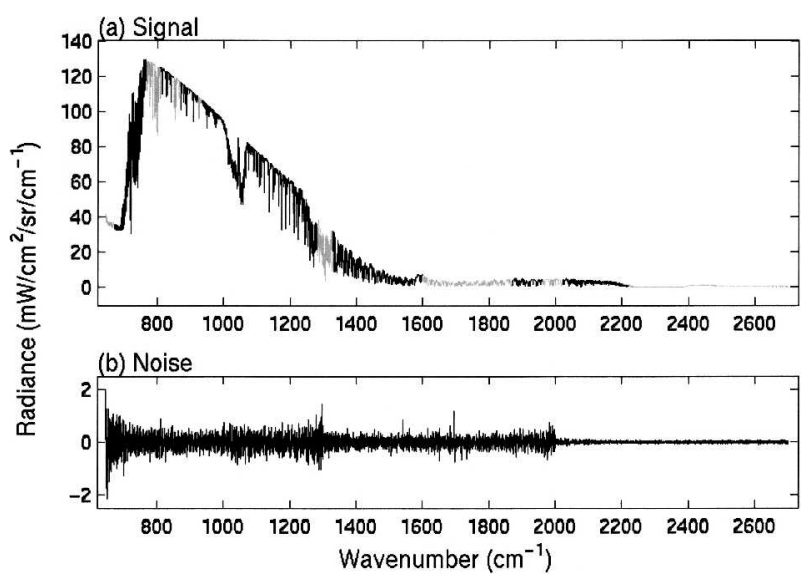

FIG. 5. (a) Simulated NAST-I spectral radiance from a radiosonde. The channels indicated in black were selected for regression analyses and retrieval; (b) typical spectrum of NAST-I random noise level for this flight as obtained from calibration blackbody looks.

requirements for EOF computation, spectral segments are chosen to contain channels that provide the most information on temperature, water vapor, ozone, carbon monoxide, and surface properties as required for accurate regression statistics. These spectral segments were selected on the basis of the retrieval sensitivity to the spectral radiances, which is illustrated by the weighting function (or Jacobian) matrix (Li 1994) computed using the fast model of Liu et al. (2003). Examples shown in Fig. 4 are the weighting function matrices for gases of constant mixing ratios (e.g., $\mathrm{CO}_{2}$ and $\left.\mathrm{N}_{2} \mathrm{O}\right)$ and for water vapor $\left(\mathrm{H}_{2} \mathrm{O}\right)$ simulated for NAST-I using the U.S. Standard Atmosphere, 1976. It is noted that the weighting functions associated with constant mixing ratio gases and water vapor have peaks distributed throughout the range of pressure altitude. In other words, the channels in these spectral regions can be used for temperature and water vapor profile retrieval. These weighting functions are also used to select the channels for the second stage matrix inversion retrieval to be discussed in the following section. The selected spectral segments for regression analyses and retrieval are indicated in Fig. 5a (darkened spectral regions), which also shows a simulated NAST-I spectrum (from an aircraft altitude of $\sim 20 \mathrm{~km}$ ) and a typical spectrum of instrument noise. NAST-I spectral channels totaling 4514 are selected and used in the regression retrieval analysis.

The optimal number of EOFs to use for the retrieval can be determined by identifying that number which minimizes the difference between radiative transfer model simulations of NAST-I radiances obtained from the retrieved atmospheric soundings and the actual observations used for the retrieval. Figure 6 shows an example of this process, based on radiance observation simulations, for two different noise situations (Zhou et al. 2002). As can be seen, the optimal number of retrieval coefficients, and therefore vertical resolution

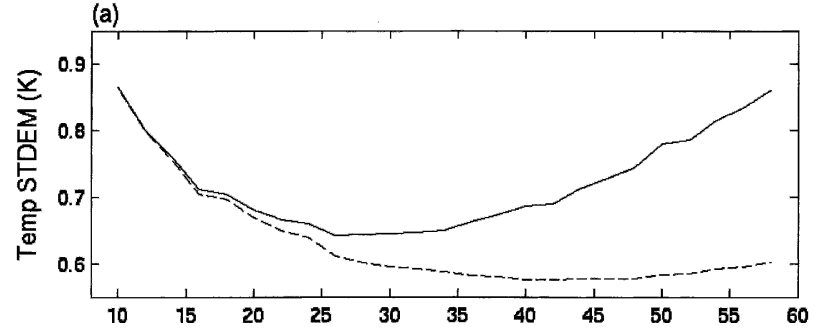

(b)

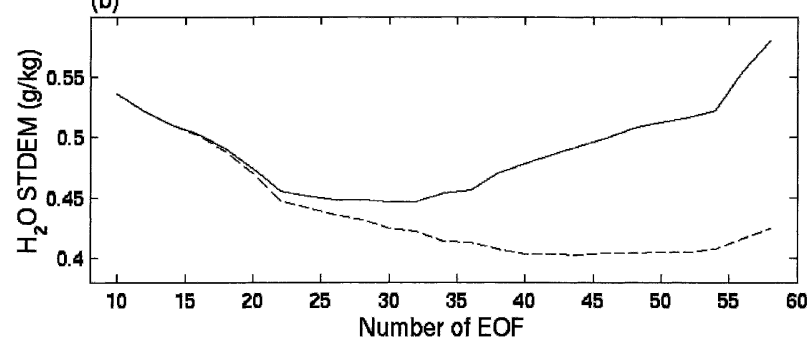

FIG. 6. Vertical mean of the profile standard deviation of the error (STDEM) for (a) temperature and (b) water vapor are shown in solid (nominal NAST-I instrument noise) and dashed curves (half-nominal NAST-I instrument noise).

and accuracy of the resulting retrievals, is sensitive to the measurement and forward model noise conditions. By basing this determination upon actual observations and radiance simulations for each particular flight situation, the dynamic variations in instrument noise and the forward model error dependence on atmospheric situation can be accounted for in the retrieval process.

As an example, Fig. 7 shows the results of 10 radiosonde comparisons with NAST-I eigenvector regression retrievals obtained during a 2002 field campaign conducted in the Florida region. Also shown to the right of each radiosonde comparison is a vertical cross section of atmospheric temperature and relative humidity, obtained from NAST-I observations within $20 \mathrm{~km}$ of the radiosonde station. The vertical cross sections display the local variability of the atmospheric structure. As can be seen, most of the differences between the radiosonde observations and the NAST-I retrieval can be explained by the local variability, even though the radiosonde is also known to have systematic errors (Turner et al. 2003). The ability to retrieve finescale vertical features of the moisture profile from NAST-I radiance spectra is evident in these comparisons. Figure 8 shows the mean and standard deviation of the NAST-I retrieval and radiosonde comparisons shown in Fig. 7. Analyses such as these have been performed for many different field campaigns, leading to the conclusion that the NAST-I eigenvector regression retrieval achieves an accuracy for temperature of $\sim 1.0^{\circ}$ $\mathrm{rms}$ error and water vapor of $\sim 20 \% \mathrm{rms}$ error for $1-\mathrm{km}$ and 2-km layers, respectively, between the surface, or a cloud layer, and the aircraft altitude. 

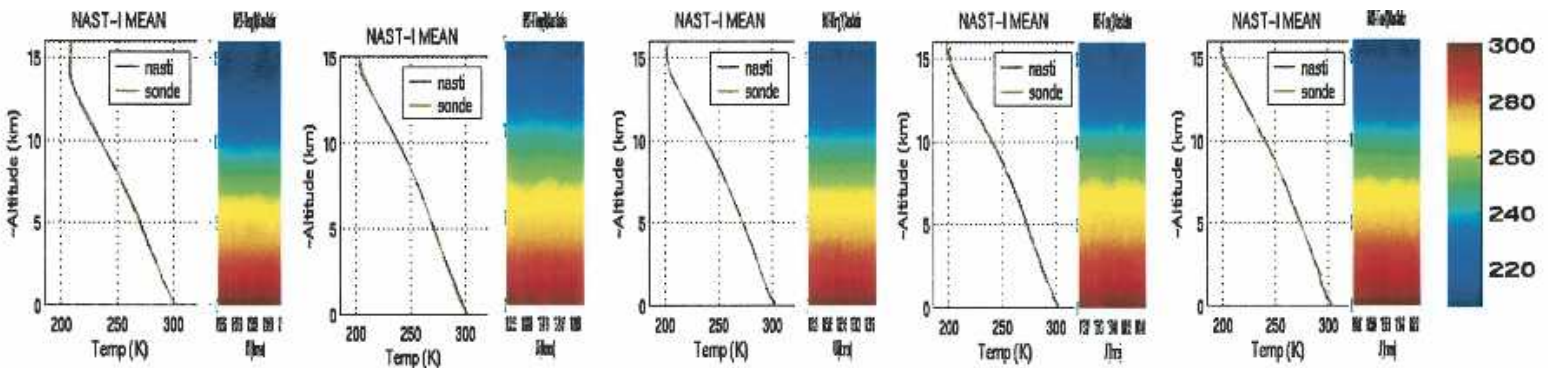

July 3

July 7

July 9

July 13
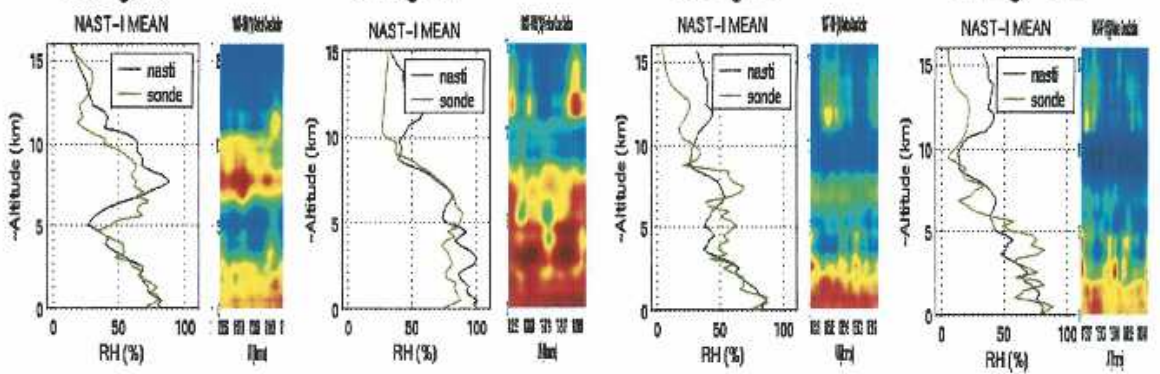

July 16
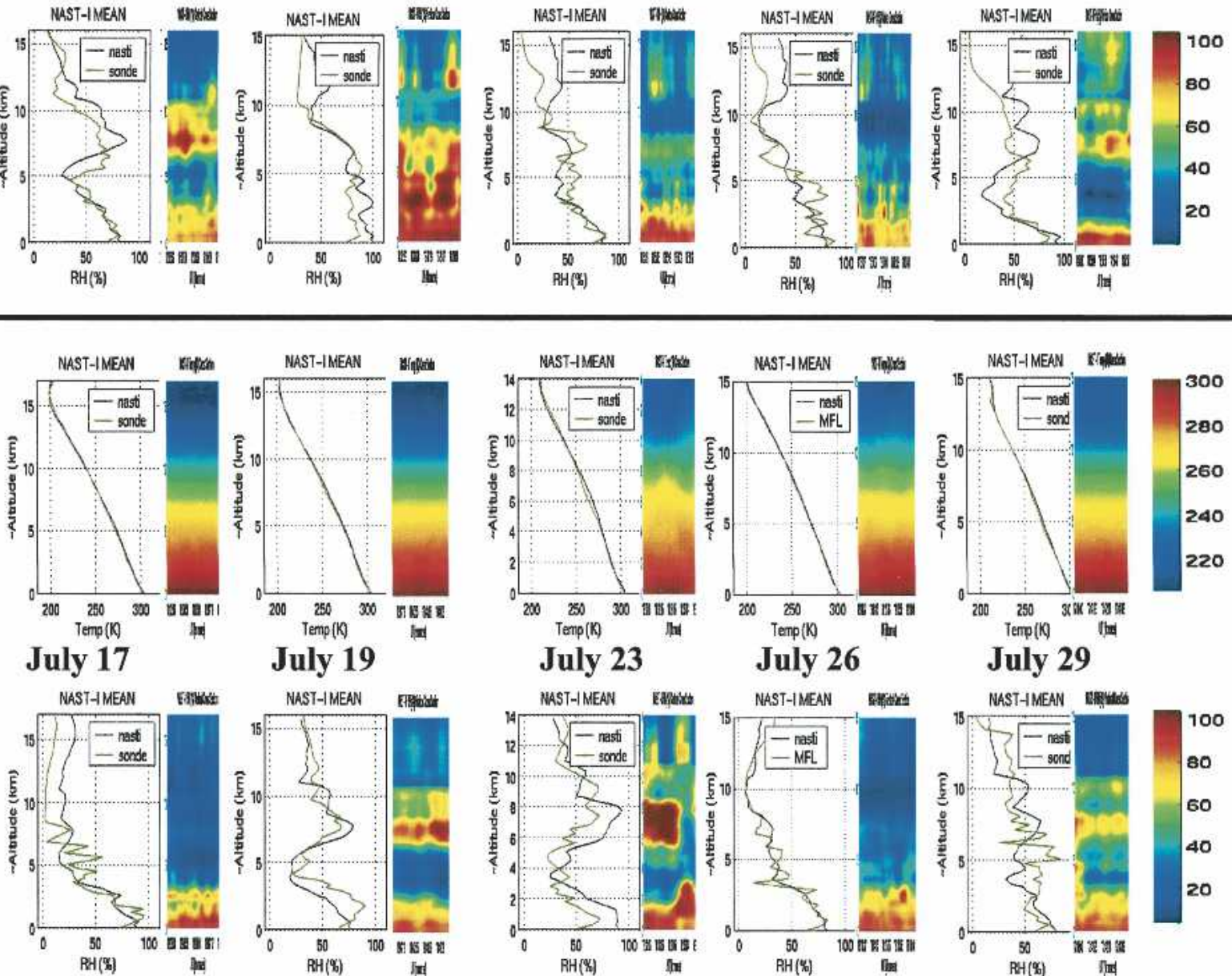

July 23

July 26
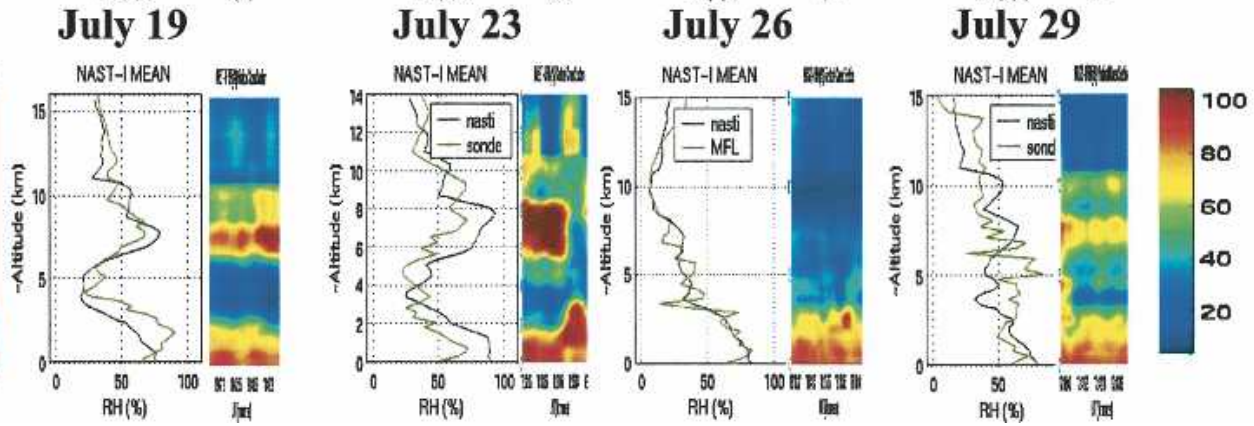

FIG. 7. Intercomparison of NAST-I sounding retrievals (black curves) with Florida radiosondes (green curves) for 10 different days during Jul 2002.

\section{b. Stage 2: Matrix inversion}

\section{1) Overview}

The matrix inversion algorithm provides a simultaneous solution for all retrieval parameters using the physically based EOF regression results as its first guess. Iteration of the matrix inversion by updating the first guess with the previous solution accounts for the nonlinearity between the radiance observations and the retrieval variables. The discrepancy principle ( $\mathrm{Li}$ and Huang 1999) is used to vary the matrix conditioning parameter for each iterative step until the radiances calculated from the retrieval fit the observed radiances to within the observational error, in a rms error sense over the spectral range used for the retrieval. Although this retrieval stage only provides a small improvement in the accuracy of the temperature profile retrievals, it is very important for enhancing the vertical resolution of water vapor, carbon monoxide (CO), and ozone $\left(\mathrm{O}_{3}\right)$ profile retrievals. Clouds are treated in a similar manner to the regression algorithm; that is, no corrections for cloud attenuation are performed so that tempera- 

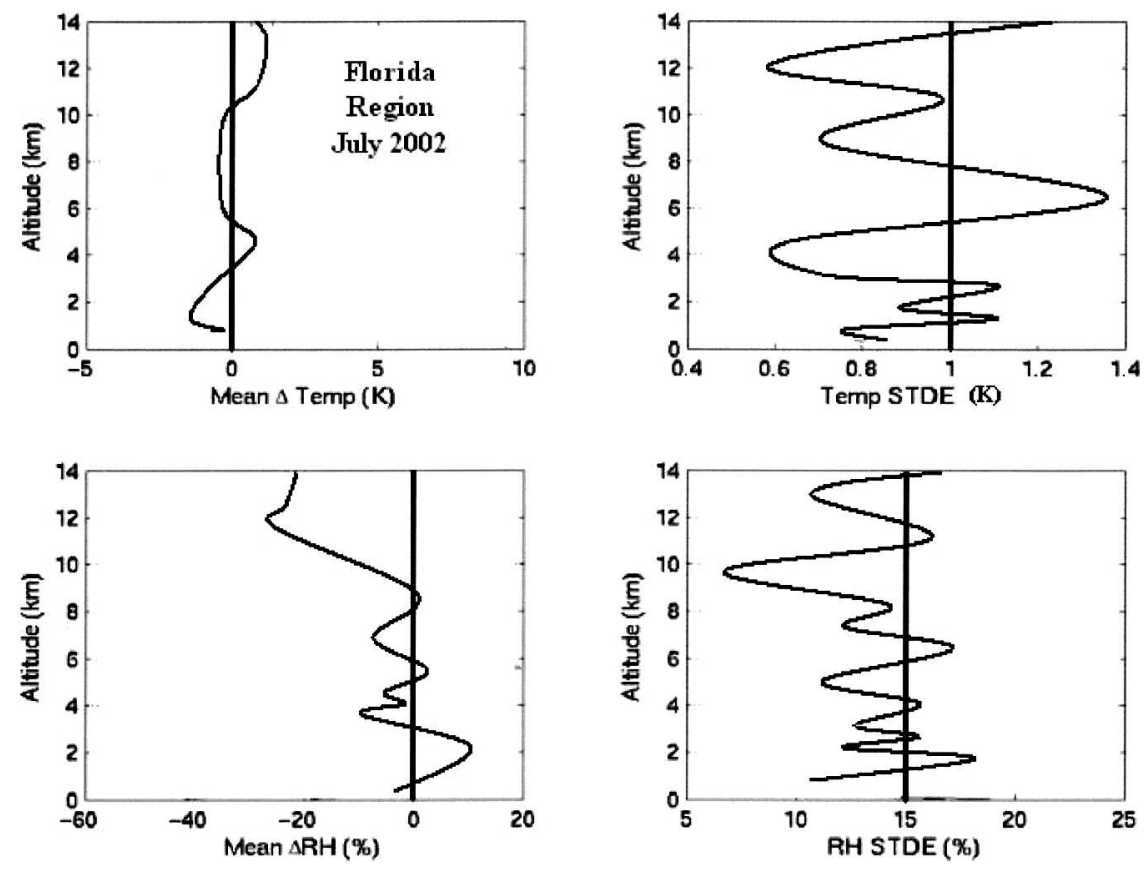

FIG. 8. Mean and standard deviation of the NAST-I and radiosonde profile measurements shown in Fig. 7.

ture and constituent profiles are retrieved that satisfy the radiance observations assuming a clear-sky atmospheric condition. Once again, this procedure enables accurate profiles down to cloud level to be obtained.

NAST-I has 8632 spectral channels providing abundant information on atmospheric parameters; however, many channels are redundant except in terms of random measurement noise. Since the initial regression retrieval has benefited from the noise reduction advantage of using most of the spectral channels, only a few hundred carefully selected (i.e., optimal) spectral channels are used for the more time-consuming matrix inversion step of the retrieval process. The optimal channels should have small detector noise, a small calibration error, and a small forward model error. These channels are desired in between line centers where the sharpest weighting functions occur. In addition, the channel set should maximize the independent spectral information for both temperature and atmospheric constituents. To use the same eigenvectors used in the regression processing to reconstruct (i.e., to reduce the noise of) NAST-I radiances for the physical retrieval, these optimal channels are selected in the same spectral regions (indicated in Fig. 5) used for the regression retrieval. The optimal channels selected for physical retrieval are shown in Fig. 9 along with a NAST-I brightness temperature spectrum.

\section{2) AnAlytical apProach}

Once the first guess is generated from the regression technique described above, a nonlinear iterative proce- dure is set up to produce a retrieval obtained by matrix inversion, which is an improvement of the first guess (i.e., the eigenvector regression retrieval). Here, the upwelling spectral radiances are represented by the radiative transfer equation (excluding any scattering and reflection),

$R-R^{s}=\varepsilon_{s} B_{s} \tau_{s}-\int_{P_{\mathrm{ac}}}^{P_{s}} B d \tau+\left(1-\varepsilon_{s}\right) \int_{P_{\mathrm{ac}}}^{P_{s}} B d \tau^{*}$,

where $\tau^{*}=\tau_{s}^{2} / \tau, R$ is the spectral radiance at a certain frequency, $R^{s}$ represents the contribution of reflected solar radiation in the infrared region and is neglected for channels with a wavelength longer than $4.5 \mu \mathrm{m}, \varepsilon_{s}$ refers to the earth's surface emissivity, $B[v, T(p)]$ is the

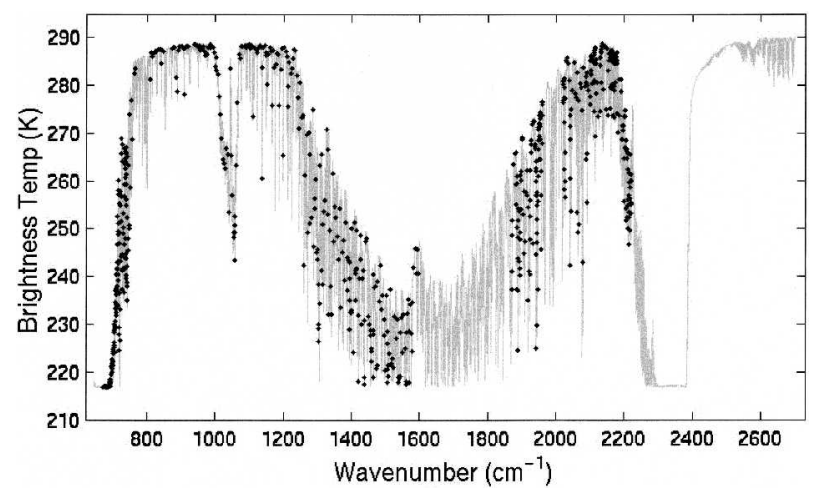

FIG. 9. NAST-I brightness temperatures and selected optimal channel index used in the physical retrieval processing. 

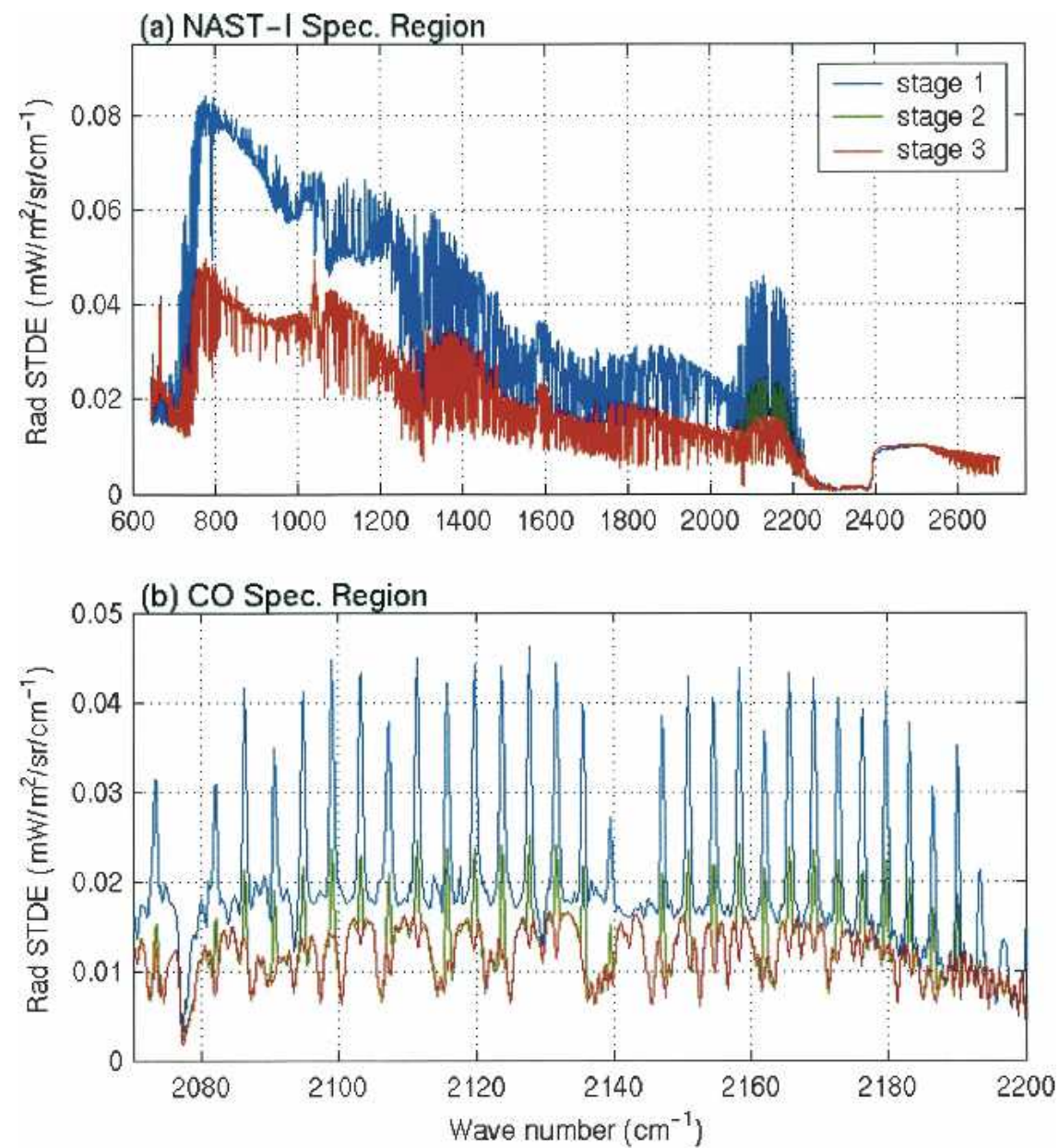

FIG. 10. Radiance standard deviation of the error (STDE) between original and retrievalsimulated radiances from three retrieval stages [(b) is the CO band region of (a)] as obtained for 14 Jul 2001 during the CLAMS field deployment. The stage 2 and stage 3 standard deviation of the errors coincide except for the $\mathrm{CO}$ region as shown in (b).

Planck function at wavenumber $v$ and at temperature $T(p), p$ is the pressure, $\tau$ is the atmospheric transmittance from any given level to the top of the atmosphere (or the sensor), $P_{\text {ac }}$ is the aircraft pressure and $P_{\mathrm{s}}$ is the surface pressure (subscript $\mathrm{s}$ denoting surface). A fast model (Liu et al. 2003) with vertical pressure coordinates from 50 to $1100 \mathrm{hPa}$ (or $\mathrm{mb}$ ) is used for the NAST-I transmittance calculation. The pressure grid is established according to $p(i)=\left(a \times i^{2}+b \times i+c\right)^{7 / 2}$, where parameters $a, b$, and $c$ are determined by solving the equation of $p(1)=1100 \mathrm{mb}, p(38)=300 \mathrm{mb}$, and $p(101)=5 \times 10^{-3} \mathrm{mb}$. The transmittance, $\tau$, is unity between the top pressure coordinate (i.e., $50 \mathrm{mb}$ ) and the aircraft level.

The radiance $R_{v}^{m}$ measured for each NAST-I channel can be considered a nonlinear function of the atmospheric temperature profile, water vapor mixing ratio profile, ozone mixing ratio profile, surface skin temperature, surface emissivity, etc. That is,
$R_{v}^{m}=R_{v}\left(T, Q, T_{s}, \varepsilon, \ldots\right)+\sigma_{\nu}\left(\sigma_{\nu}\right.$ is the instrument and forward model noise). In general,

$$
\mathbf{Y}^{m}=\mathbf{Y}(\mathbf{X})+\sigma,
$$

where the state vector $\mathbf{X}$ contains atmospheric temperatures ( $L$ levels of atmosphere), atmospheric moisture mixing ratios (the moisture is expressed as the logarithm of the mixing ratio in practical applications), one surface skin temperature, etc., and $\mathbf{Y}^{m}$ contains $N$ (number of channels used) observed radiances. The linear form of Eq. (5) is

$$
\delta \mathbf{Y}=\mathbf{Y}^{\prime} \delta \mathbf{X},
$$

where $\mathbf{Y}^{\prime}$ is the linear tangent of the forward model $\mathbf{Y}$, the weighting function (or Jacobian) matrix. An accurate and efficient analytical way to calculate the weighting functions is very important for real-time advanced sounder data retrieval processing. Here the linear 

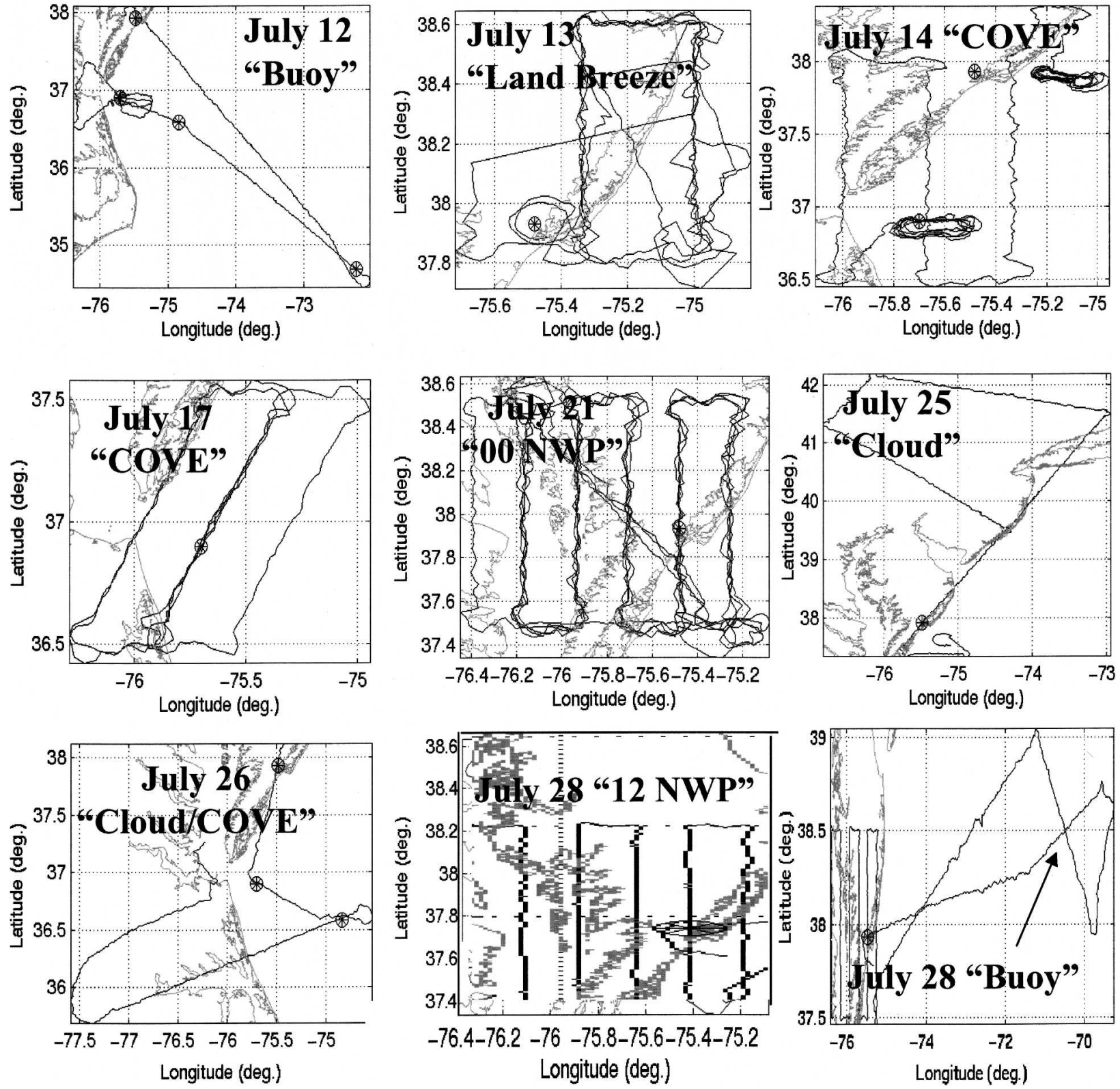

FIG. 11. Proteus flight tracks for CLAMS during Jul 2001 as displayed by NAST-I nadir field-of-view positions. The irregularities in the tracks are due to the changing roll angle of the aircraft.

model $\mathbf{Y}^{\prime}$ uses an efficient analytical form ( $\mathrm{Li}$ et al. 2000). A general form of the minimum variance solution minimizes the following penalty function (Rodgers 1976):

$$
\begin{aligned}
\mathbf{J}(\mathbf{X})= & {\left[\mathbf{Y}^{m}-\mathbf{Y}(\mathbf{X})\right]^{\mathrm{T}} \mathbf{E}^{-1}\left[\mathbf{Y}^{m}-\mathbf{Y}(\mathbf{X})\right] } \\
& +\left[\mathbf{X}-\mathbf{X}_{0}\right]^{\mathrm{T}} \mathbf{H}\left[\mathbf{X}-\mathbf{X}_{0}\right],
\end{aligned}
$$

where superscript $\mathrm{T}$ denotes the transpose. By using the Newtonian iteration,

$$
\mathbf{X}_{n+1}=\mathbf{X}_{n}+\mathbf{J}^{\prime \prime}\left(\mathbf{X}_{n}\right)^{-1} \mathbf{J}^{\prime}\left(\mathbf{X}_{n}\right),
$$

the following quasi-nonlinear iterative form (Eyre 1989) is obtained:

$$
\delta \mathbf{X}_{n+1}=\left(\mathbf{Y}_{n}^{\prime \mathrm{T}} \mathbf{E}^{-1} \mathbf{Y}_{n}^{\prime}+\mathbf{H}\right)^{-1} \mathbf{Y}_{n}^{\prime \mathrm{T}} \mathbf{E}^{-1}\left(\delta \mathbf{Y}_{n}+\mathbf{Y}_{n}^{\prime} \delta \mathbf{X}_{n}\right),
$$

where $\delta \mathbf{X}_{n}=\mathbf{X}_{n}-\mathbf{X}_{0}, \delta \mathbf{Y}_{n}=\mathbf{Y}^{m}-\mathbf{Y}\left(\mathbf{X}_{n}\right), \mathbf{X}$ is the atmospheric profile to be retrieved, $\mathbf{X}_{0}$ is the initial state of the atmospheric profile or the first guess, $\mathbf{Y}^{m}$ is the vector of the observed radiances or brightness temperatures used in the retrieval process, $\mathbf{E}$ is the observation error covariance matrix that includes instrument 


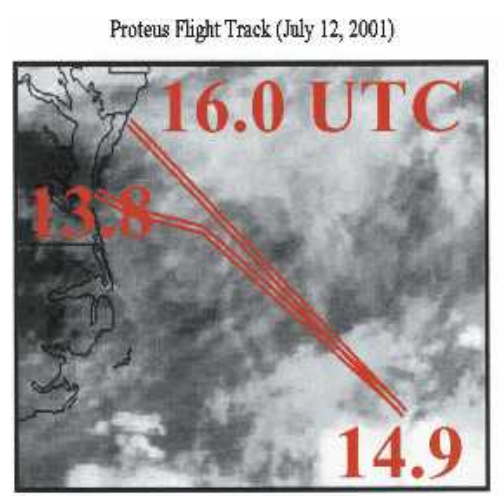

GOES IR (1515 GMT)

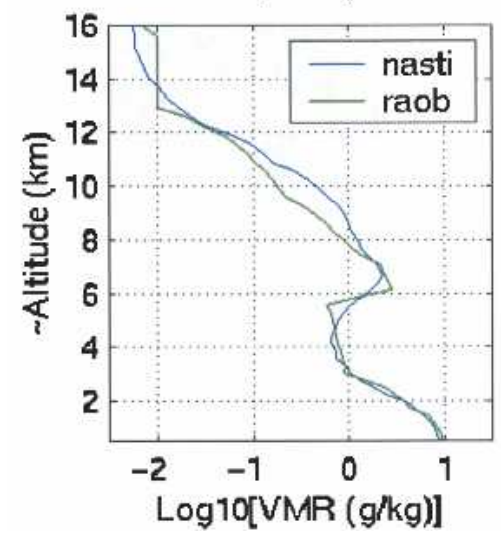

NAST-ITemperature(K) Vertica) Cross Section

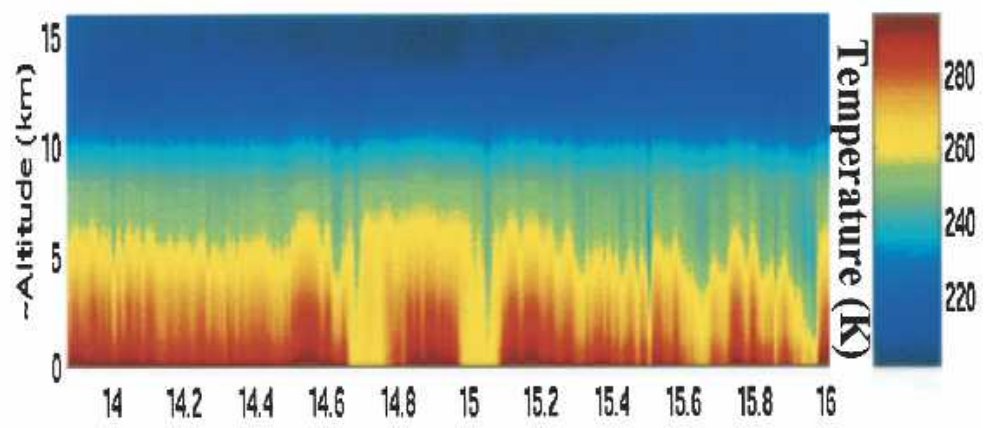

NAST-ILogiquMR (gkg)) Vetcical Cross Section

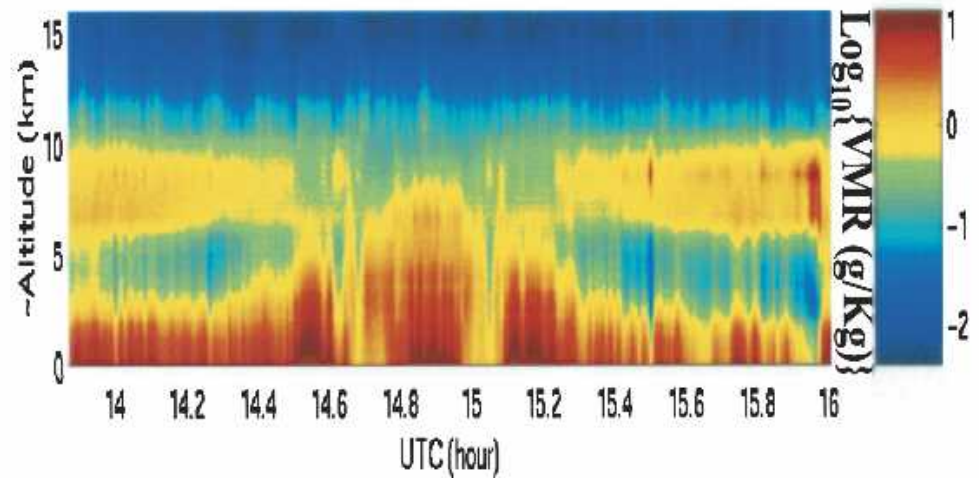

FIG. 12. GOES IR image of cirrus cloud cover associated with Proteus flight track for 12 Jul 2001 and vertical cross sections of retrieved temperature and humidity profiles showing the effects of clouds on the retrievals of temperature and moisture. A clear-sky comparison with the Wallops Island radiosonde is shown to validate the structure observed below the cirrus with NAST-I.

noise and forward model error, and $\mathbf{H}$ is the a priori matrix that constrains the solution. Here, $\mathbf{H}$ can be the inverse of the a priori first-guess error covariance matrix or a scaled identity matrix. If the statistics of both the measurement and a priori error covariance matrix are Gaussian, then the maximum likelihood solution is obtained. However, if the a priori error covariance matrix is not known or is estimated incorrectly, the solution will be suboptimal (Eyre 1989). Usually $\mathbf{H}=\gamma \mathbf{l}$ is applied in Eq. (9), where $\gamma$ is a Lagrangian multiplier that serves as a smoothing factor. Equation (9) becomes

$$
\delta \mathbf{X}_{n+1}=\left(\mathbf{Y}_{n}^{\prime \mathrm{T}} \mathbf{E}^{-1} \mathbf{Y}_{n}^{\prime}+\gamma \mathbf{l}\right)^{-1} \mathbf{Y}_{n}^{\prime \mathrm{T}} \mathbf{E}^{-1}\left(\delta \mathbf{Y}_{n}+\mathbf{Y}_{n}^{\prime} \delta \mathbf{X}_{n}\right)
$$

The smoothing factor $\gamma$ is very difficult to determine but extremely important to the solution. It is noted that $\gamma$ is dependent upon the observations, the observation error, and the first guess of the atmospheric profile; often it is chosen empirically (Smith et al. 1985; Hayden 1988). The solution can be overconstrained, producing large biases in the retrieval when $\gamma$ is too large. The solution can be underconstrained and unstable when $\gamma$ is too small. In the NAST-I retrieval procedure, the discrepancy principle, following Li and Huang (1999), is applied to determine the appropriate smoothing factor $\gamma$. Thus,

$$
\left\|\mathbf{Y}[\mathbf{X}(\gamma)]-\mathbf{Y}^{m}\right\|^{2}=\sigma^{2},
$$

where $\sigma^{2}=\sum_{k=1}^{N} e_{k}^{2} e_{k}$ is the square root of the diagonal of $\mathbf{E}$ or the observation error of channel $k$. Here, $\mathbf{E}$ includes instrument error (e.g., Fig. 5b) and forward model error (i.e., $e_{k}^{2}=\eta_{k}^{2}+f_{k}^{2}$, where $\eta_{k}$ is the instrument noise of channel $k$, while $f_{k}$ is the forward model error that is assumed to be $0.5 \mathrm{~K}$ for the same channel). Usually $\sigma^{2}$ can be estimated from the instrument noise and the validation of the atmospheric transmittance model used in the retrieval. Since Eq. (11) has a unique solution for $\gamma$, the atmospheric parameters and the smoothing factor can be determined simultaneously. In NAST-I retrieval processing, a simple numerical approach is adopted for solving Eq. (11); $\gamma$ is changed in each iteration according to

$$
\gamma_{n+1}=q_{n} \gamma_{n}
$$

where $q$ is a factor for increasing or decreasing $\gamma$. Based on Eq. (11), $q$ is obtained in each iteration by satisfying the following conditions: 


\section{(a) GOES Band 1 at 16:15 UT}

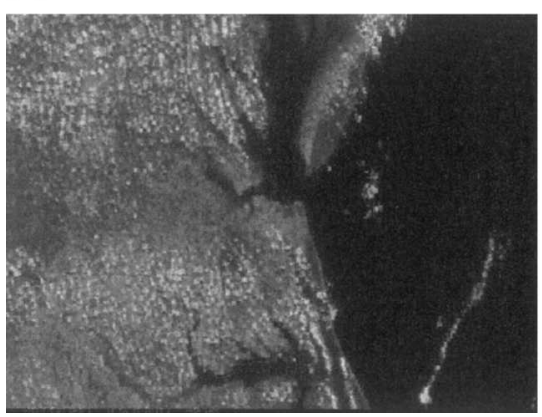

(b) GOES Band 1 at 16:45 UT

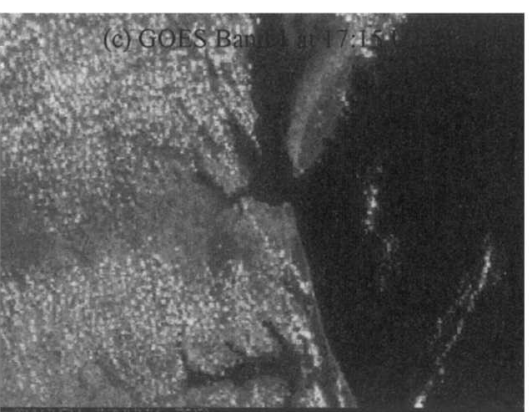

(c) GOES Band 1 at 17:15 UT

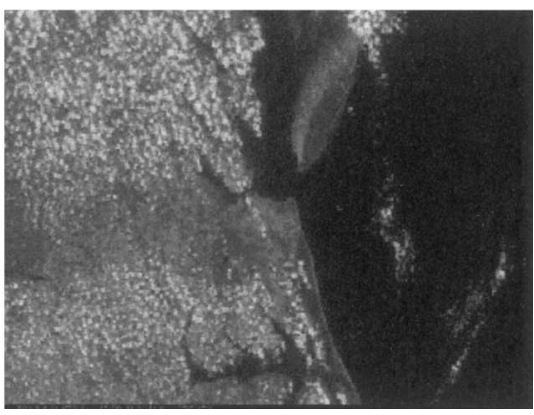

FIG. 13. GOES images of $14 \mathrm{Jul} 2001$ indicating clear-sky conditions with moisture and few clouds moving into the area with northwest wind.

$$
\begin{aligned}
& q_{0}=1.0 ; \\
& \text { if }\left\|\mathbf{Y}\left(\mathbf{X}_{n}\right)-\mathbf{Y}^{m}\right\|<\sigma^{2} \text {, then } q_{n}=1.5 ; \\
& \text { if }\left\|\mathbf{Y}\left(\mathbf{X}_{n}\right)-\mathbf{Y}^{m}\right\|=\sigma^{2} \text {, then stop the iteration; } \\
& \text { if }\left\|\mathbf{Y}\left(\mathbf{X}_{n}\right)-\mathbf{Y}^{m}\right\|>\sigma^{2} \text {, then } q_{n}=0.5 .
\end{aligned}
$$

The $q$ factor has been found from empirical experience to ensure that the solution is stable between iterations. Thus, $\gamma$ keeps changing until the iteration stops.
In the retrieval processing, several checks are made for retrieval quality control. The rms of the quantity $\left[\mathbf{Y}\left(\mathbf{X}_{i}\right)-\mathbf{Y}^{m}\right]$, computed for all selected channels, is computed to check for convergence (or divergence). If the $n$th iteration produces a divergent solution, then the iteration is stopped and the retrieval is set to the first guess (or the previous $n-1$ atmospheric state); otherwise iterations continue until $\chi_{n}<1.0 \mathrm{~K}$ and $\left|\chi_{n}-\chi_{n-1}\right|$ $<0.01 \mathrm{~K}$, or a maximum of 10 iterations is reached. The degree of convergence of each iteration depends on the
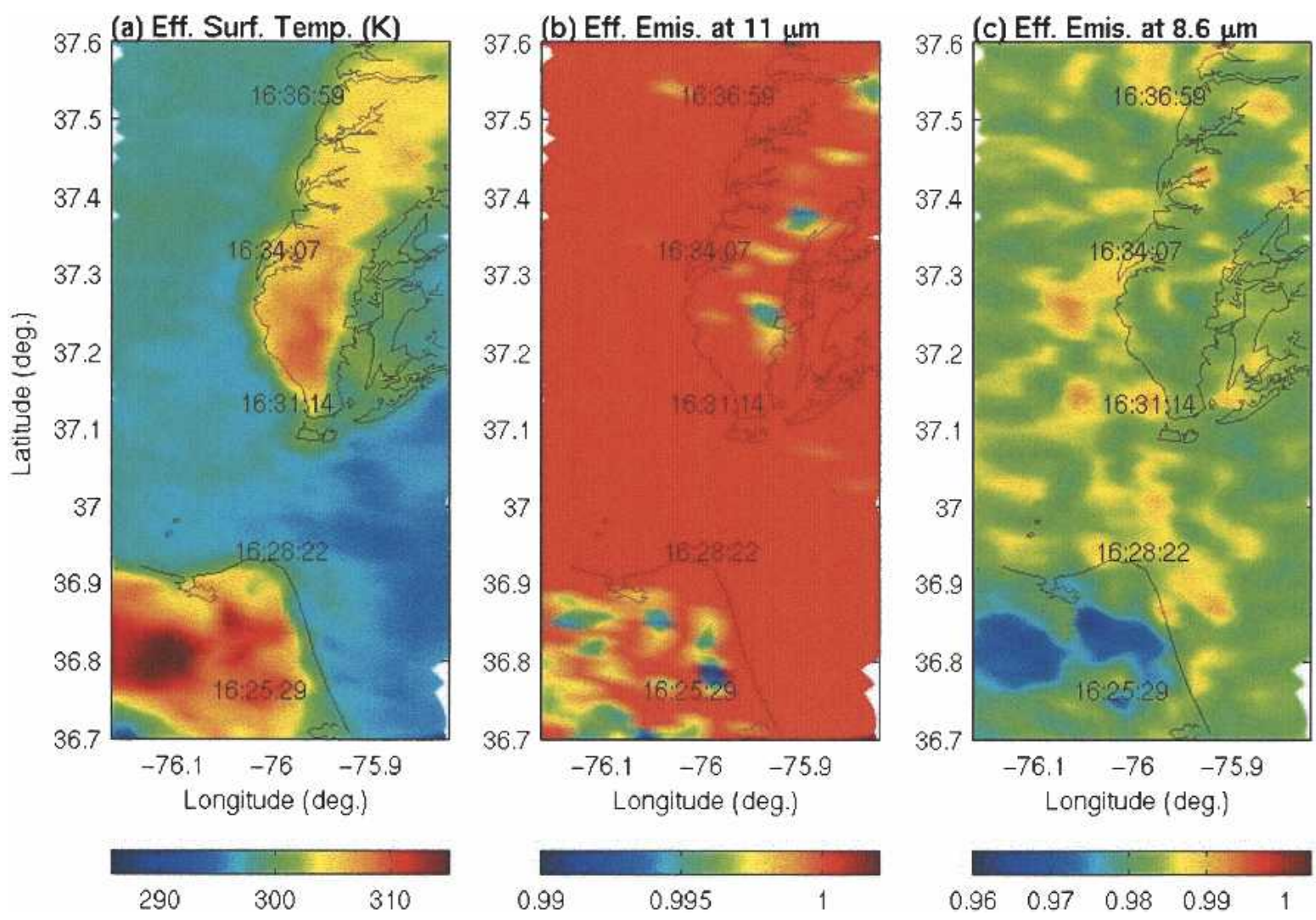

FIG. 14. Retrieved surface properties from the NAST-I flight on $14 \mathrm{Jul} 2001$. The UTC associated with geophysical location is indicated in the figure. 

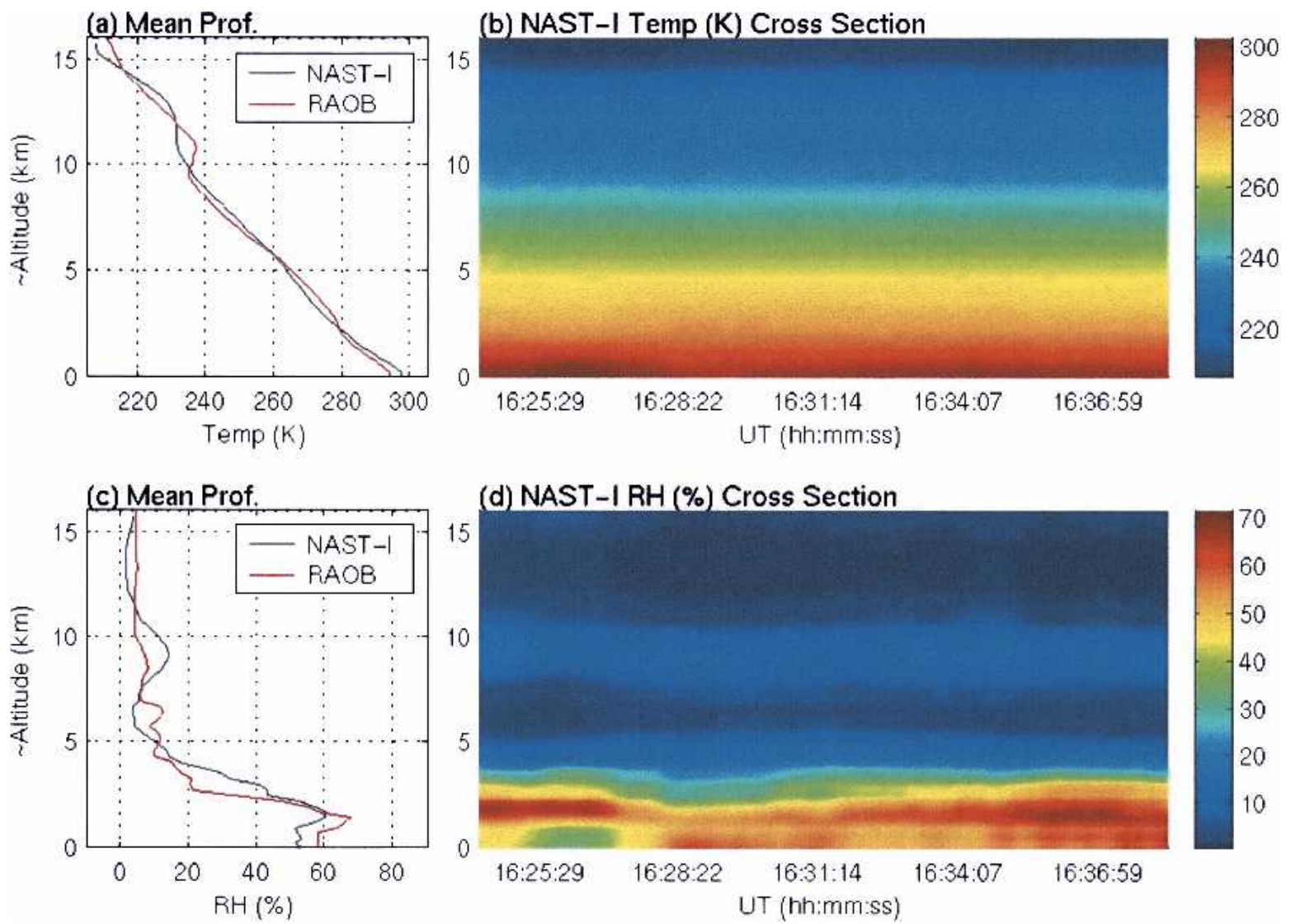

FIG. 15. Retrieved temperature and relative humidity profiling (nadir mode) cross sections of the NAST-I observations associated with Fig. 14. The cross-sectional mean is plotted against a nearby radiosonde observation.

accuracy of the previous atmospheric and surface state. In addition, at each iteration, each level of the water vapor profile is checked for supersaturation. A unit relative humidity is assumed at any supersaturated level.

\section{c. Stage 3: Iterative adjustment}

A final stage of the profile retrieval process involves an enhancement of the $\mathrm{CO}$ mixing ratio profile provided by applying the matrix inverse method to only radiances observed within "clean" spectral channels for that gas. A clean $\mathrm{CO}$ spectral channel radiance is defined as one in which the radiance is only influenced by surface contribution and $\mathrm{CO}$ emission and absorption. In this final stage, the retrieval is performed by matrix inversion, as in the second stage, but here all parameters, other than the $\mathrm{CO}$ mixing ratio profile, are held constant during the iterative process. The procedure is described in detail by Zhou et al. (2004).

Figure 10 shows the standard deviation between the observed NAST-I radiance spectra and the radiances calculated from the NAST-I retrievals after each stage of the retrieval process. As can be seen, there are significant improvements in the radiance fit for all spectral regions, except the $15-\mu \mathrm{m}$ and $4.3-\mu \mathrm{m}$ carbon dioxide absorption regions, as a result of the matrix inverse step in the retrieval process. In the $\mathrm{CO}$ region both the stage 2 and stage 3 matrix inverse solutions provide a major improvement to the $\mathrm{CO}$ profile retrieval accuracy (Zhou et al. 2005).

\section{Observations during CLAMS}

During the CLAMS experiment the Proteus flew nine flights in which the NAST-I achieved radiance spectra for the derivation of surface and atmospheric variables. The flight patterns are shown in Fig. 11. The scientific objectives can be categorized as being focused on overflying the surface-based instruments at the Chesapeake Light platform (which supports the COVE), overflying ocean buoys, or obtaining data to study the land breeze phenomenon and to initialize numerical weather prediction (NWP) models. There was also one flight (i.e., 25 July 2001) dedicated to sampling cirrus cloud properties.

\section{a. Cloud effects}

The vertical cross sections of temperature and moisture retrieved along the flight tracks of 12 July 2001, 

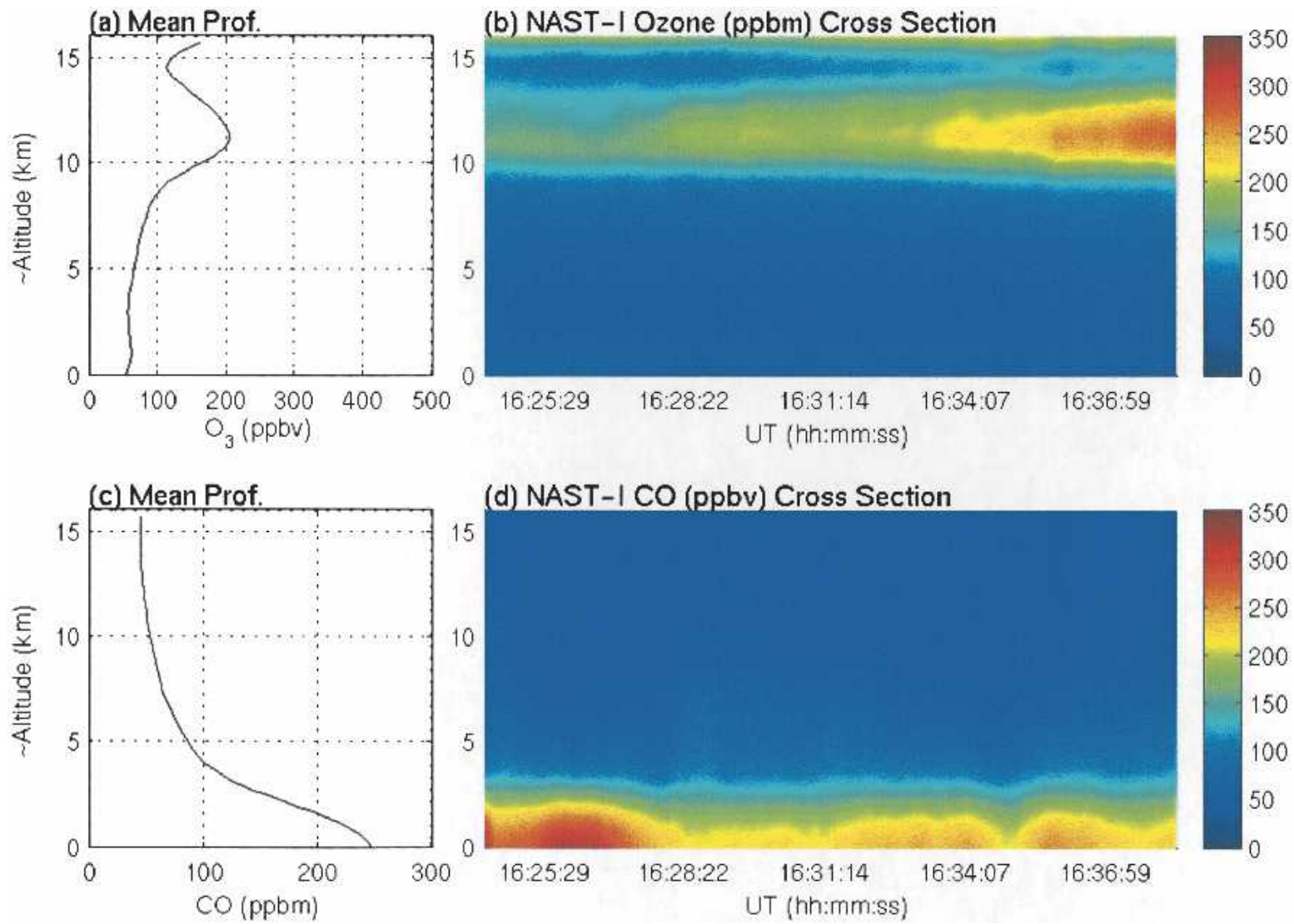

FIG. 16. Retrieved ozone and carbon monoxide profiling (nadir mode) cross sections of the NAST-I observations associated with Figs. 14 and 15.

over the cirrus cloud cover, are shown in Fig. 12. The cross sections reveal the attenuation of temperature and moisture signal by the cirrus cloud. The moisture cross section indicates that the top of the cirrus cloud is at about the 9-km level and extends downward to about the $6-\mathrm{km}$ level. Below $6 \mathrm{~km}$ there is a layer of dry air extending down to a layer of moisture whose top is at 2 $\mathrm{km}$ (i.e., the marine boundary layer) at the northern end of the track and extends upward to the cirrus level at the southern end of the track (the middle of Fig. 12) where deep convection is occurring. As can be seen from Fig. 12, important moisture features below a scattered and semitransparent cirrus cloud deck are resolved using the NAST-I infrared observations. The result is analogous to viewing an object through a window with partially open venetian blinds. Further validation of this conclusion is shown by comparison of the retrievals at the northern end of the cross section, where clear skies exist, with the nearby Wallops Island radiosonde observation, also shown in Fig. 12. It is noted that, since the lower-tropospheric thermal feature signal is inherent in the spectral radiance data for partially cloudy and semitransparent cirrus cloud situations, "cloud clearing" techniques (Smith 1968) can be used to filter out any cloud artifacts (i.e., the venetian blind effect) from the sounder data, but this procedure was not incorporated within this analysis.

\section{b. Case study example}

An example of NAST-I data collected from the CLAMS field campaign, results for 14 July 2001 are provided to illustrate the characteristics of retrievals obtained during CLAMS. Typical retrieval products from NAST-I observed radiances are surface skin temperature, the surface emissivity spectrum, and atmospheric profiles of temperature, moisture, and the chemical species, $\mathrm{O}_{3}$ and $\mathrm{CO}$. The Geostationary $\mathrm{Op}$ erational Environmental Satellite-8 (GOES-8) observation, shown in Fig. 13, reveals the cloud conditions during the 14 July 2001 period of NAST-I observations. Corresponding to the GOES images, Fig. 14 shows that the NAST-I retrieved surface properties of skin temperature and emissivity correspond well to surface types such as land and water. Relatively warmer skin temperatures are shown over the land, as opposed to water, as expected under daytime viewing conditions. The smaller emissivities of the street and building materials associated with the city of Norfolk, Virginia (lower-left region), are clearly evident. NAST-I retrieved surface skin temperature at the NOAA buoy 

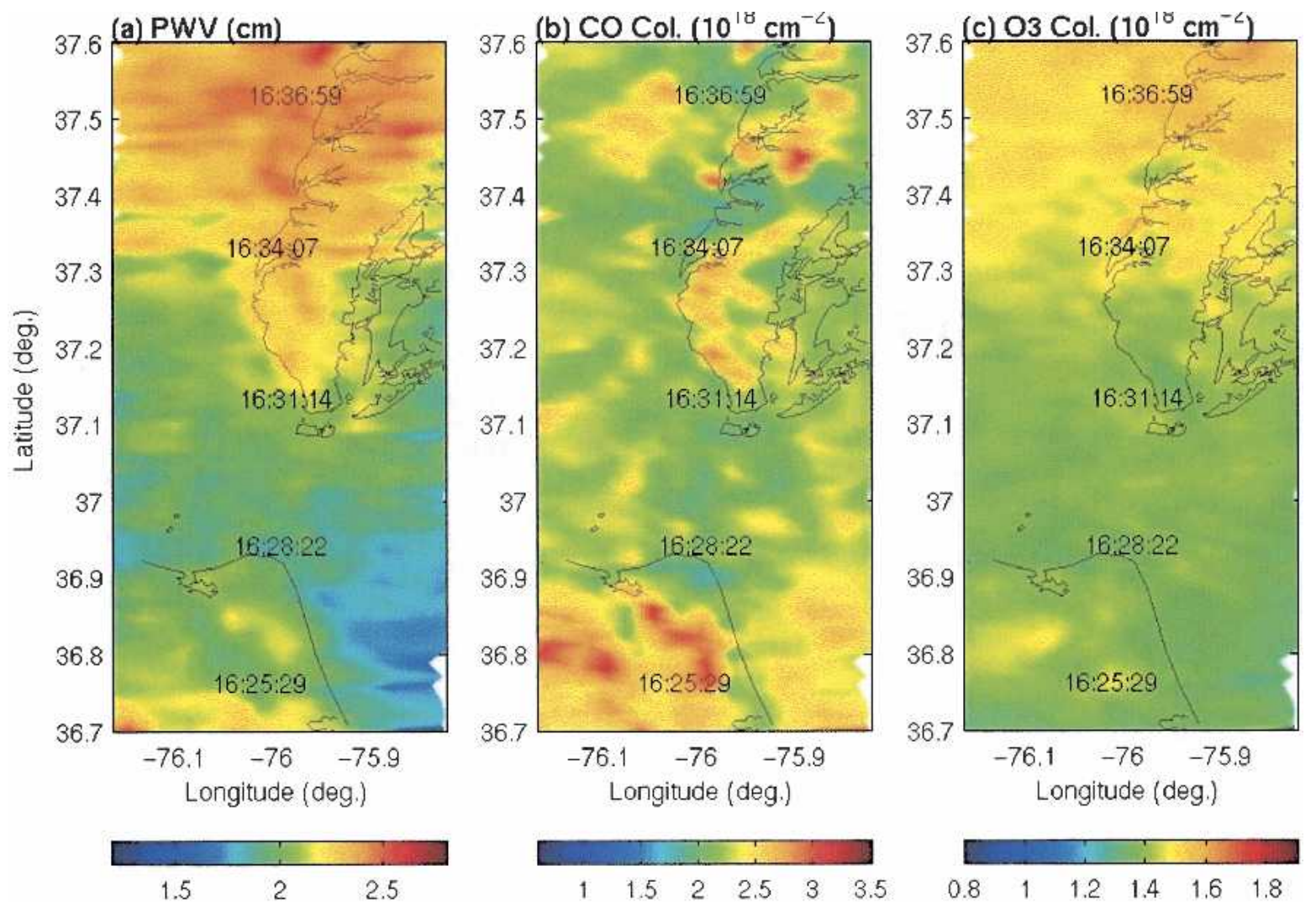

FIG. 17. NAST-I (14 Jul 2001) retrieved (a) PWV (with a mean of $1.99 \mathrm{~cm}$ ), (b) CO column densities (with a mean of $2.0 \times 10^{18}$ $\mathrm{cm}^{-2}$ ), and (c) $\mathrm{O}_{3}$ column densities (with a mean of $1.5 \times 10^{18} \mathrm{~cm}^{-2}$ ).

site is $296.23 \mathrm{~K}$ (with a standard deviation of $0.21 \mathrm{~K}$ ), as compared to the NOAA Chesapeake light buoy measured bulk surface temperature of $297.45 \mathrm{~K}$. The cold "skin," observed by NAST-I relative to the subsurface water observed by the buoy is expected as a result of evaporative cooling (Smith et al. 1996).

The atmospheric vertical sounding distributions along the aircraft flight track are shown in Fig. 15. The universal time is associated with the location shown in Fig. 14. The mean profiles of temperature and water vapor cross sections are compared with the nearby radiosonde observations (red curve). The vertical distributions of $\mathrm{CO}$ and $\mathrm{O}_{3}$ are shown in Fig. 16. The horizontal distributions of the precipitable water vapor (PWV) and the total column amounts of $\mathrm{CO}$ and $\mathrm{O}_{3}$ (from $200 \mathrm{mb}$ to the surface) derived from the vertical profiles of temperature, water vapor, $\mathrm{CO}$, and $\mathrm{O}_{3}$ are shown in Fig. 17. The PWV derived from the COVE radiosonde is $1.91 \mathrm{~cm}$, which is in good agreement with NAST-I inferred PWV in Fig. 17a, with a mean of 1.99 $\mathrm{cm}$ and a gradient in which relatively higher PWV exists toward the north. The column densities of $\mathrm{CO}$ and $\mathrm{O}_{3}$ are shown in Figs. 17b and 17c, respectively; NAST-I retrieved CO column, with a mean of $2.0 \times 10^{18} \mathrm{~cm}^{-2}$, favors a clean $\mathrm{CO}$ background during the summer season with very little latitude dependence in this region.
The $\mathrm{O}_{3}$ column density with a mean of $1.5 \times 10^{18} \mathrm{~cm}^{-2}$ shows a gradient in which the $\mathrm{O}_{3}$ increases toward the north.

NAST-I thermodynamic parameters have been validated with radiosonde profiles (Fig. 15) but the trace gas retrievals shown here cannot be validated because of the lack of in situ verification measurements for these gases. However, the close radiance agreement between the observed radiance spectra and those simulated from the retrievals (Fig. 10) indicates that the total column amounts of $\mathrm{CO}$ and $\mathrm{O}_{3}$ must be accurately determined; this is justified by noting that the surface and atmospheric thermodynamic state data used in simulation were those retrieved from NAST-I and, as just mentioned, already validated with nearby radiosonde measurements.

\section{Conclusions}

NAST-I has successfully participated in the CLAMS field campaign, and geophysical parameters were retrieved in support of the CLAMS experiment. NAST-I mapped the surface skin temperature and atmospheric profiles of temperature, water vapor, and chemical pollutants such as carbon monoxide and ozone throughout 
the CLAMS experiment. The NAST-I geophysical products for the CLAMS are available, upon e-mail request (Daniel.K.Zhou@nasa.gov), for their use in scientific studies. More detailed investigations on the use of multi-instrument and multiplatform data, gathered during CLAMS, together with model simulations, are underway.

Acknowledgments. The authors gratefully acknowledge the National Polar-orbiting Operational Environmental Satellite System Integrated Program Office for supporting the NAST program, including the development of the NAST-I instrument, its airborne deployments, and the analysis of the data obtained during important scientific field programs, such as the CLAMS reported here. The Massachusetts Institute of Technology Lincoln Laboratory produced the NAST-I instrument. ABB Bomem Incorporated provided the dynamically aligned Michelson interferometer subsystem. The Space Science and Engineering Center of the University of Wisconsin-Madison developed the NAST-I instrument internal calibration blackbody hardware and associated radiometric calibration processing system. The NASA Langley Research Center maintains the NAST-In instrument, manages the field deployments of the NAST system, and together with the University of Wisconsin and the Massachusetts Institute of Technology, provided the personnel who supported Proteus aircraft instrument operations during the CLAMS. The Scaled Composites Incorporated, who developed the Proteus aircraft, conducted the NAST science flights during the CLAMS. Our appreciation is extended to all the individuals, too numerous to mention here, who have contributed to the highly successful NAST program.

\section{REFERENCES}

Cousins, D., and W. L. Smith, 1997: National Polar-orbiting Operational Environmental Satellite System (NPOESS) Airborne Sounder Testbed-Interferometer (NAST-I). Proc. SPIE, 3127, 323-331.

Eyre, J. R., 1989: Inversion of cloudy satellite sounding radiances by nonlinear optimal estimation. I: Theory and simulation for TOVS. Quart. J. Roy. Meteor. Soc., 115, 1001-1026.

Goldberg, M. D., Y. Qu, L. M. McMillin, W. Wolf, Z. Lihang, and M. Divakarla, 2003: AIRS near-real-time products and algorithms in support of operational numerical weather prediction. IEEE Trans. Geosci. Remote Sens., 41, 379-389.

Hayden, C. M., 1988: GOES-VAS simultaneous temperaturemoisture retrieval algorithm. J. Appl. Meteor., 27, 705-733.

Li, J., 1994: Temperature and water vapor weighting functions from radiative transfer equation with surface emissivity and solar reflectivity. Adv. Atmos. Sci., 11, 421-426.

— from satellite sounder measurements using the discrepancy principle. Appl. Opt., 38, 916-923.

, W. W. Wolf, W. P. Menzel, W. Zhang, H. L. Huang, and T. H. Achtor, 2000: Global soundings of the atmosphere from
ATOVS measurements: The algorithm and validation. $J$. Appl. Meteor., 39, 1248-1268.

Liu, X., J.-L. Moncet, D. K. Zhou, and W. L. Smith, 2003: A fast and accurate forward model for instrument, NAST-I. Proc. Fourier Transform Spectroscopy and Optical Remote Sensing of Atmosphere, OSA Topical Meetings, Quebec, Canada, OSA.

Moncet, J. L., and Coauthors, 2004: Algorithm theoretical basis document (ATBD) for the Cross Track Infrared Sounder (CrIS). Volume 2: Environmental data records, Version 4.0, AER, 152 pp.

Revercomb, H. E., and Coauthors, 1998: Recent results from the Scanning High-Resolution Interferometer Sounder (HIS) aircraft instrument. Proc. Eighth Int. Workshop on Atmospheric Science from Space Using Fourier Transform Spectrometry, Toulouse, France, 16-18.

Rodgers, C. D., 1976: Retrieval of atmospheric temperature and composition from remote measurements of thermal radiation. Rev. Geophys. Space Phys., 14, 609-624.

Salisbury, J. W., and D. M. D'Aria, 1992: Emissivity of terrestrial materials in the 8-14 micron atmospheric window. Remote Sens. Environ., 42, 83-106.

Smith, W. L., 1968: An improved method for calculating tropospheric temperature and moisture from satellite radiometer measurements. Mon. Wea. Rev., 96, 387-396.

- and H. M. Woolf, 1976: The use of eigenvectors of statistical covariance matrices for interpreting satellite sounding radiometer observations. J. Atmos. Sci., 33, 1127-1140.

,-- C. M. Hayden, and A. J. Schreiner, 1985: The simultaneous export retrieval package. Tech. Proc. Second Int. TOVS Study Conf., Igls, Austria, CIMSS, 224-253.

_ , and Coauthors, 1996: Observations of the infrared radiative properties of the ocean-Implications for the measurement of the sea surface temperature via satellite remote sensing. Bull. Amer. Meteor. Soc., 77, 41-51.

_ , and Coauthors, 1999: NAST-I: Results from revolutionary aircraft sounding spectrometer. Proc. SPIE, 3756, 2-8.

- , D. K. Zhou, F. W. Harrison, H. E. Revercomb, A. M. Larar, A. H. Huang, and B. Huang, 2001: Hyperspectral remote sensing of atmospheric profiles from satellites and aircraft. Proc. SPIE, 4151, 94-102.

— , and Coauthors, 2001: The Chesapeake Lighthouse and Aircraft Measurements for Satellites (CLAMS) experiment. Preprints, 11th Conf. on Satellite Meteorology and Oceanography, Madison, WI, Amer. Meteor. Soc., 492-495.

Turner, D., B. Lesht, A. Clough, J. Liljegren, H. Revercomb, and D. Tobin, 2003: Dry bias and variability in Vaisala RS80-H radiosondes: The ARM experience. J. Atmos. Oceanic Technol., 20, 117-132.

Wark, D. Q., and H. E. Fleming, 1966: Indirect measurements of atmospheric temperature profiles from satellite: I. Introduction. Mon. Wea. Rev., 94, 351-362.

Wilber, A. C., D. P. Kratz, and S. K. Gupta, 1999: Surface emissivity maps for use in satellite retrievals of longwave radiation. NASA Tech. Publication NASA/TP-1999-209362, 35 pp. [Available from National Technical Information Service, 5285 Port Royal Road, Springfield, VA 22161.]

Zhou, D. K., and Coauthors, 2002: Thermodynamic product retrieval methodology for NAST-I and validation. Appl. Opt., 41, 6957-6967.

, W. L. Smith, A. M. Larar, M. A. Avery, J. Li, X. Liu, J.-L. Moncet, and N. S. Pougatchev, 2003: NAST-I remote sensing and carbon monoxide. Proc. SPIE, 4891, 127-135.

,-- X. Liu, J. Li, A. Larar, and S. Mango, 2005: Tropospheric CO observed with NAST-1: Retrieval analyses and first results. Appl. Opt., in press. 